\title{
الاستعمار الاستيطاني في فلسطين بين البنية والصيرورة: محو وإزالة أهم تحكمم وسيطرة؟
}

\section{Settler Colonialism in Palestine between Structure and Process: Elimination or Power and Control?}

$$
\begin{aligned}
& \text { ملخص: تهدف هذه الدراسة إلى التعرف إلى منطق الاستعمار الاستيطاني في فلسطين، للإجابة }
\end{aligned}
$$

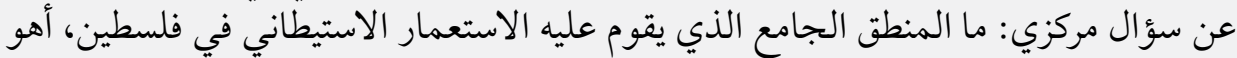

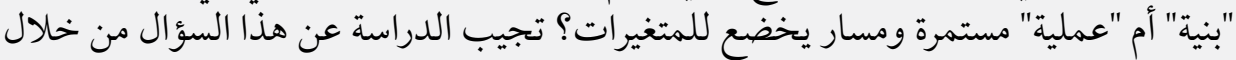

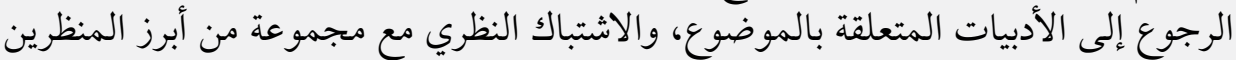

$$
\begin{aligned}
& \text { في مجاله، خاصة في ما يتعلق بالاحتلال الإسرائيلي لمناطق 1967. }
\end{aligned}
$$

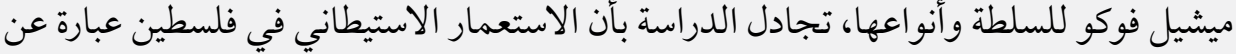

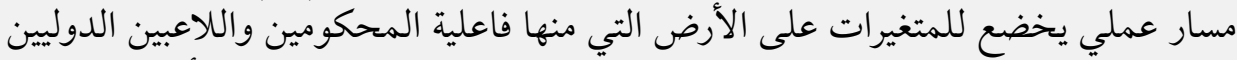

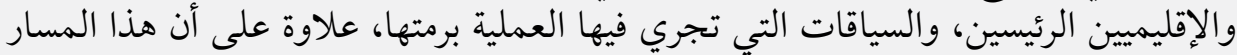

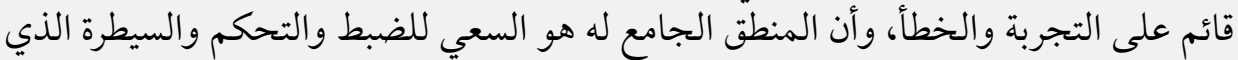

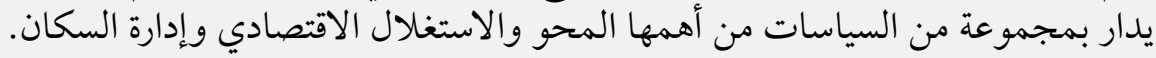

$$
\begin{aligned}
& \text { كلمات مفتاحية: إسرائيل، الاستعمار، الاستيطان، المحو، السيط السيطرة، البيوسلطة. }
\end{aligned}
$$

Abstract: This paper seeks to answer the central question: Is settler colonialism in Palestine a "structure" or an ongoing "process"? The paper engages with most prominent theorists in the field of settler colonialism, with a special focus on the nature of the Israeli occupation of the West Bank and Gaza. By employing Michel Foucault's concept of power and its types, the study argues that settler colonialism in Palestine is a process rather than a structure. It is subject to transformations on the ground, including the agency of the governed and the attitudes of major international and regional players, and the contexts in which the entire process takes place. Settler-colonialism as a process shaped by trial and error. Its overriding logic is the pursuit of power and control, facilitated by policies that most importantly include elimination, economic exploitation and population management.

Keywords: Israel, Colonialism, Settlement, Erasure, Control, Bio-Power.

$$
\text { * محاضر في قسمي الفلسفة والدراسات الثقافية، وعلم الاجتماع، في جامعة بيرزيت، فلسطين. }
$$

Lecturer in the Departments of Philosophy, Cultural Studies, and Sociology, Birzeit University, Palestine. 


$$
\text { هو -النهر الذي تنزلون فيه للمرة الثانية ليس النهي }
$$

\section{مقدمة}

ثمة سجال نظري حول المنطق الجامع للاستعمار الاستيطاني في فلسطين، ففي حين يجادل

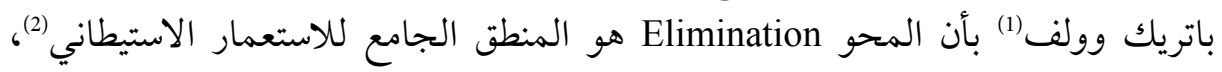

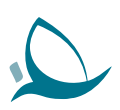

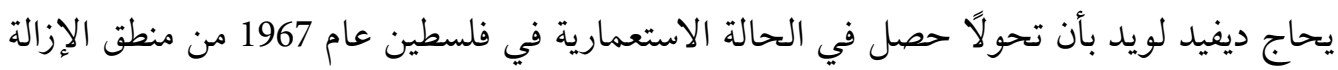

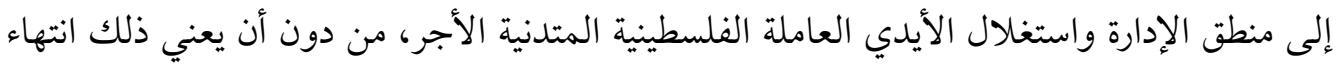

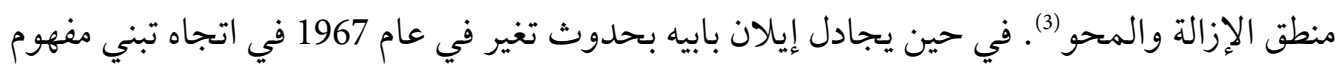

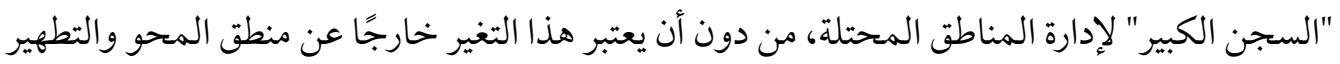

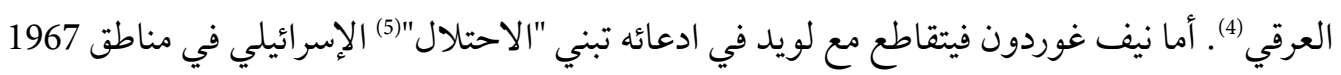

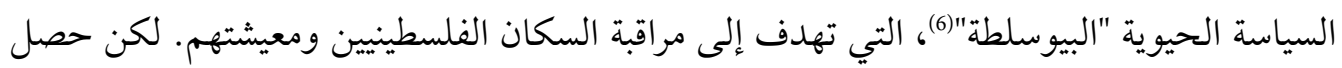

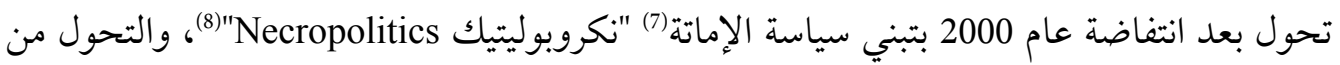
الاستعمار إلى مبدأ الفصل (9).

في المقابل، يستخدم إيليا زريق مصطلح "الاستعمار الهجين" لتوصيف الحالة الاستعمارية في وهني

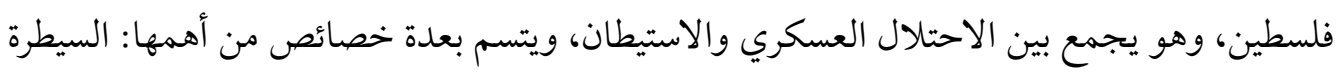

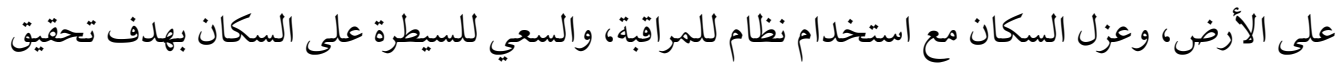
(1) حول نقد كتابات وولف، ينظر : أشرف بدر وعاصم خليل، "الاستعمار الاستيطاني في السياق الفلسطيني: براديغم أم مفهوم؟"،

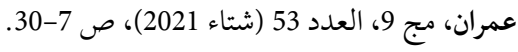

(2) Patrick Wolfe, "Settler Colonialism and the Elimination of the Native," Journal of Genocide Research, vol. 8, no. 4 (2006).

(3) David LIoyd, "Settler Colonialism and the State of Exception: The Example of Palestine/ Israel," Settler Colonial Studies, vol. 2, no. 1 (2012), p. 67.

(4) Ilan Pappe, The Biggest Prison on Earth: A History of the Occupied Territories (London: Oneworld Publications, 2017), p. 4.

(5) يجب أن نشير إلى تحفظّنا على استخدام مصطلح "الاحتلال" لوصف الحالة الاستعمارية في الضفة الغربية وقطاع غزة؛ إذ رغم

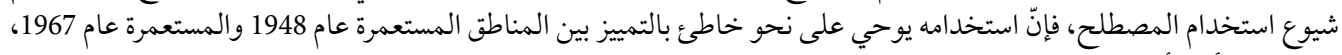

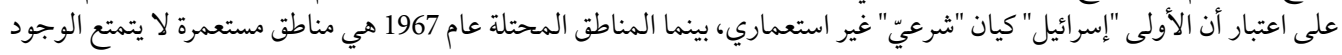
الإسرائيلي فيها بـ "الشرعية". (6) مصطلح استخدمه ميشيل فوكو لوصف تحكّم السلطة في الجسد الاجتماعي (السكّان).

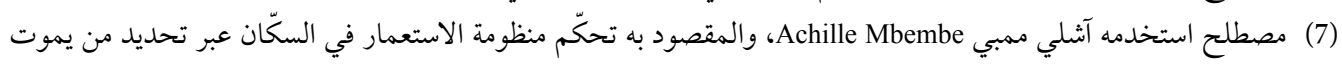
ومن يعيش.

(8) Neve Gordon, Israel's Occupation (Berkeley/ London: University of California Press, 2008), p. 2.

(9) Ibid., p. 208. 
التوازن الديموغرافي (10). وتتبعه هنيدة غانم في استخدام المصطلح نفسه معتبرة أن النظام الإسرائيلي في فلسطين "نظام هجين" متعدد الأدوات، يدمج بين الاستعمار الاستيطاني والاحتلال العسكري والأبارتهايد(11). في حين يجادل مارسيلو سفيرسكي ورونين بن آري بأن الاستعمار الاستيطاني الصهيوني يتلبس منطق "المحو المزدوج"؛ محو الحياة الأصلانية ومحو الحياة المشتركة بين اليهود والعرب(12)، قبل مجيء الاستعمار الاستيطاني الصهيوني إلى فلسطين، وذلك بهدف تحقيق الفصل

والإخضاع (13).

تهلفف هذه الدراسة إلى تحليل مفهوم الاستعمار الاستيطاني في فلسطين، بافتراض أنه مفهوم واسع

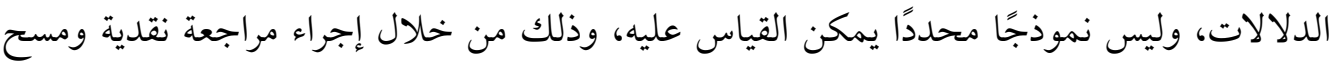

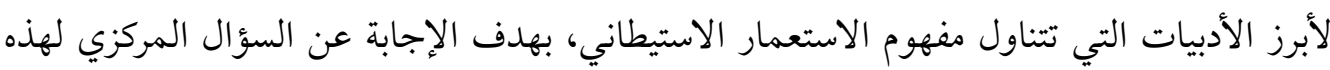
الدراسة وهو: ما المنطق الجامع الذي يقوم عليه الاستعمار الاستيطاني في فلسطين؟ باعتبار أن كثيرًا من الأدبيات التي تتناول الاستعمار الاستيطاني في فلسطين تستند إلى مقولة وولف بأنه مبني على فئى فئي منطق المحو.

تستخدم الدراسة منهجية متعددة التخصصات، سواء بالرجوع إلى بعض المواد الأرشيفية المتعلقة بالموضوع، أو الاشتباك النظري مع أبرز المنظرين الذين تناولوا مفهوم الاستعمار الاستيطاني والاحتلال الإسرائيلي لمناطق 1967، وفي مقدمتهم وولف، ولورينزو فيراشيني، وسارة روي، ونيف غوردون، وغيرشون شافير، وإيلان بابيه. والاستعانة بمفهوم ميشيل فوكو Michel Foucault للسلطة وأنواعها.

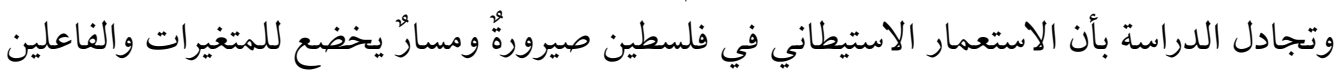
على الأرض والظروف المحيطة، وأنه قائم على التجربة والخطأ، وأن المنطق الجامع للاستعمار الاستيطاني الصهيوني في فلسطين هو السعي للتحكم والضبط والسيطرة، وأنه في هذا السياق يوظف عدة استراتيجيات من بينها المحو والاستغلال الاقتصادي وإدارة السكان، لتحقيق مصلحة الحيقي الحركة الصهيونية؛ فالذي يحدد الأداة هو مدى ملاءمتها لتحقيق أهداف الاستعمار الاستيطاني الصهيوني المتمثلة في إقامة دولة "يهودية".

تستكشف الدراسة المنطق الجامع للاستعمار الاستيطاني الصهيوني من خلال تتبع مساره على نحو

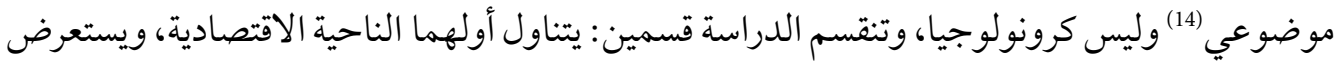

$$
\text { (10) إيليا زريق، "الصهيونية والاستعمار"، عمران، مج 2، العدد } 8 \text { (ربيع 2014)، ص 7 7-34. }
$$

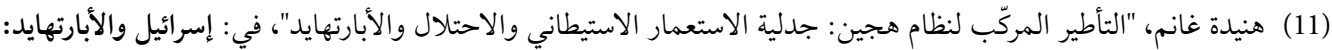

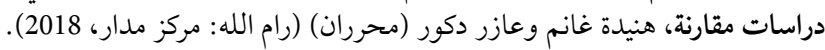

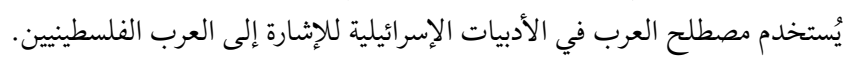

(13) Marcelo Svirsky \& Ronnen Ben-Arie, From Shared Life to Co-Resistance in Historic Palestine (London/ New York: Rowman \& Littlefield International Ltd, 2018).

$$
\text { المقصود التتبع على أساس الموضوع وليس التسلسل الزمني. }
$$


ثانيهما العنف الاستعماري في مختلف مراحله، وهي: مرحلة اليشوف(15)، ومرحلة ما بعد إقامة الدولة،

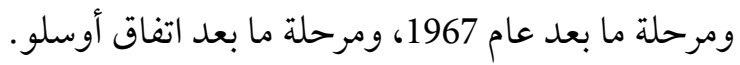

\section{أولاً: العـلاقة الاقتصادية بين المستعـمـر والمستتعَمَر والتحولات في الينية}

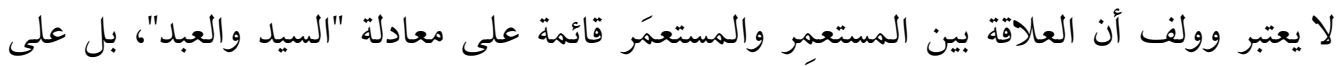

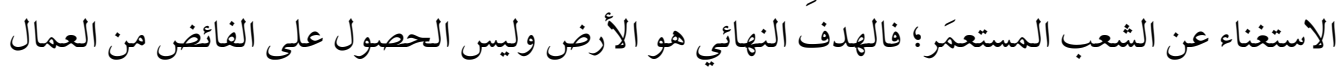

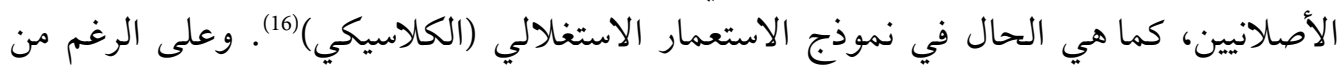

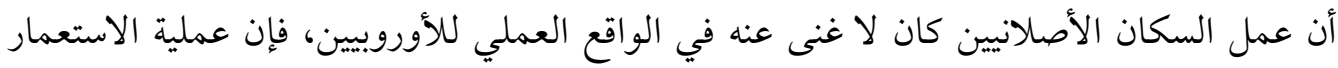

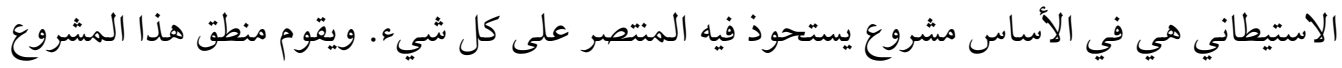

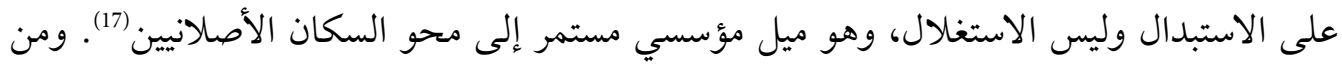

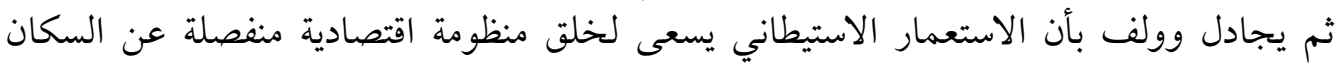

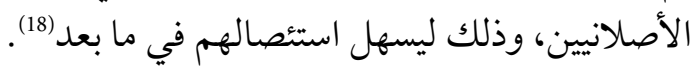

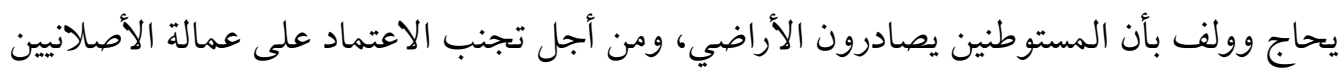

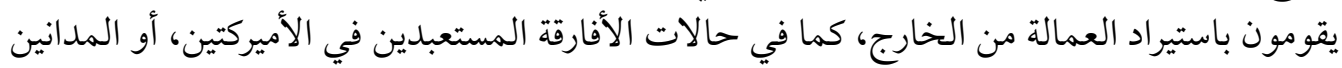

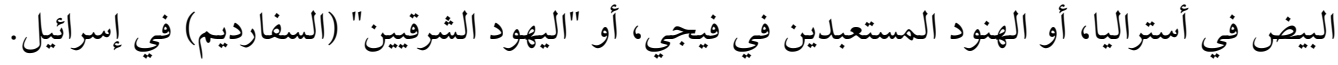

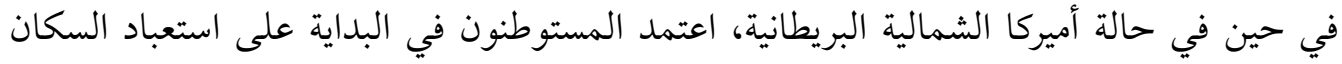

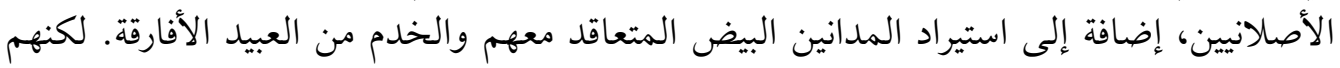

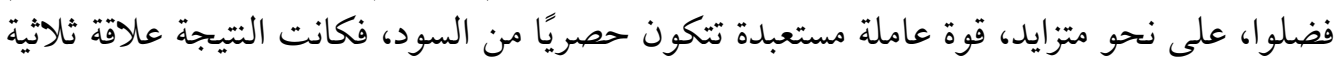

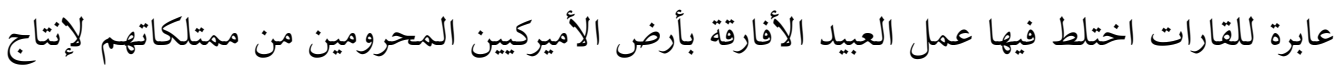

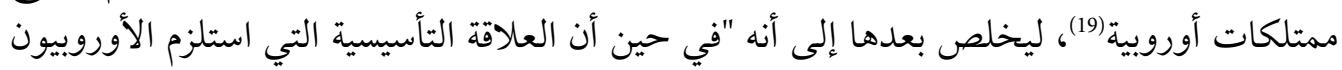

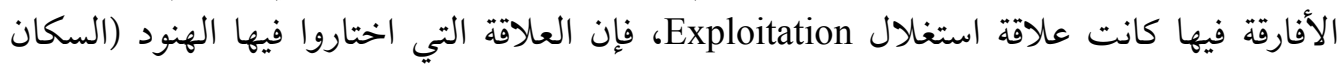

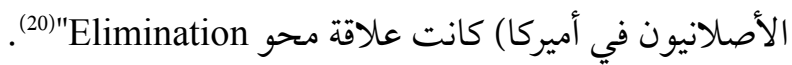

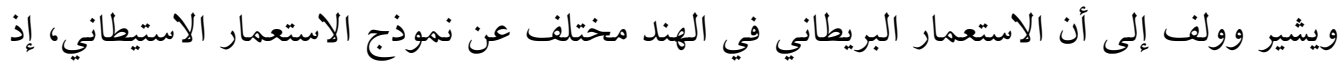

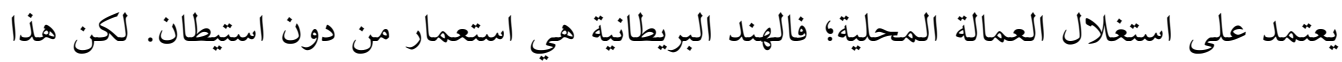

$$
\text { (15) مصطلح يطلق على الاستيطان الاستعماري لفلسطين في الفترة 1882-1948. }
$$

(16) Patrick Wolfe, Settler Colonialism and the Transformation of Anthropology (London/ New York: Cassell, 1999), p. 2.

(17) Ibid., p. 163

(18) Patrick Wolfe, "Settler Colonialism and the Elimination of the Native," Journal of Genocide Research, vol. 8, no. 4 (2006), p. 396.

(19) Patrick Wolfe, "Race and the Trace of History: For Henry Reynolds," in: Fiona Bateman \& Lionel Pilkington (eds.), Studies in Settler Colonialism: Politics, Identity and Culture (New York: Palgrave Macmillan, 2011), p. 273.

(20) Ibid., p. 276. 
لا يعني أن البريطانيين الأفراد لا يمكن أن ينتهي بهم الأمر إلى الاستيطان هناك، فالعديد من المزارعين وغيرهم فعلوا ذلك، ولا يعني كذلك أن "الراج البريطاني" لم يقضِ على رعنى رعاياه من المستعمَرين، إذ إنه إنه

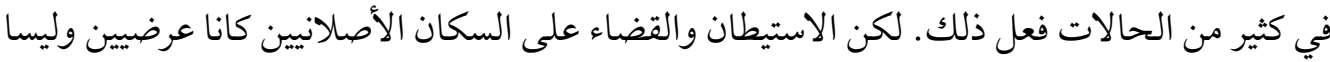
محوريين في المشروع الاستعماري البريطاني في الهند، بعكس نموذج الاستعمار الاستيطاني (21). يستدرك وولف في مقارنته الاستعمار الاستيطاني في فلسطين به في الجزائر وجنوب أفريقيا، اللذين

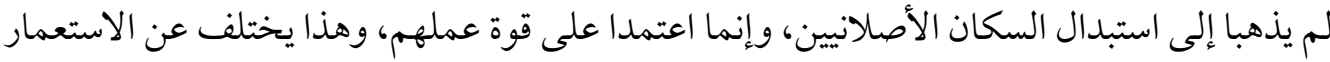
الاستيطاني على الرغم من وجود استيطان، ويمكن أن يطلق عليه (مستوطنات فيها مستوطنون) الإسئ Colonies with Settlers in them الإسرائيليون على نحو كبير في ظل غياب بدائل من الشرقيين (المزراحيم) والروس. لكن إسرائيل

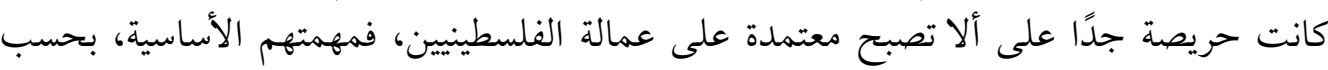
الحركة الصهيونية، ليست العمل بل الاختفاء، فهي لم تكن تنوي استيعاب السكان الأصلانيين (22. يحث فيراشيني على فهم العلاقة الديالكتيكية بين الاستعمار (الكلاسيكي/ الاستغلالي) والاستعمار

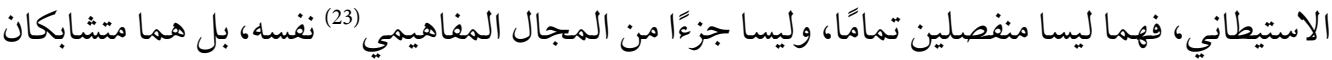

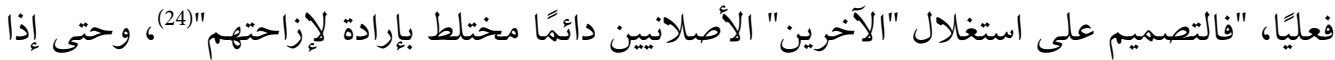
كان ينبغي النظر إلى التشكيلات الاستعمارية والاستعمار الاستيطاني على أنها منفصلة وجوديًا، فينبغي عدم التقليل من تكاملها النهائي داخل الإمبريالية.

"ليس لدينا طريقة لفهم الوضع الحالي بالكامل ما لم نعتبر عملية الاستعمار الاستيطاني

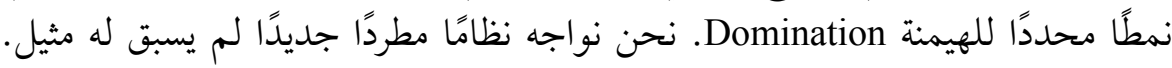
هنا يصبح الاختلاف البنيوي بين الاستعمار والاستعمار الاستيطاني حاسمًا من الناحية

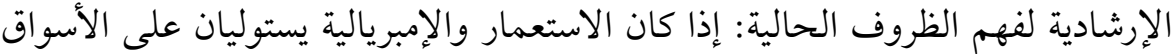
والعمل لغرض الاستغلال والاستغلال الحصري على التوالي، فإن الاستعمار الاستيطاني

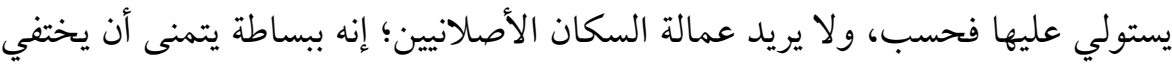

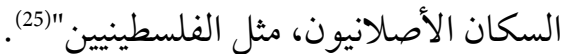

(21) Ibid., p. 286.

(22) "CASAR Lecture - Comparing Colonial and Racial Regimes," YouTube, 17/6/2013, accessed on 22/12/2021, at: https://bit.ly/3EwCQZz

(23) Lorenzo Veracini, "Settler Colonialism: Career of a Concept," The Journal of Imperial and Commonwealth History, vol. 41, no. 2 (2013), p. 314.

(24) Lorenzo Veracini, The Settler Colonial Present (New York: Palgrave Macmillan, 2015), p. 26.

(25) Ibid., p. 93.

$$
\text { وقد سبقه لهذا الاستنتاج جميل هلال، ينظر: }
$$
Jamil Hillal, "Imperialism and Settler Colonialism in West Asia: Israel and the Arab Palestinian Struggle," University of Dar es Salaam Journals, vol. 1, no. 1 (1976), p. 53. 
استدخلت عدة دراسات مقولة وولف بأن الاستعمار الاستيطاني "بنية وليس حدثًا"(26)، التي توحي

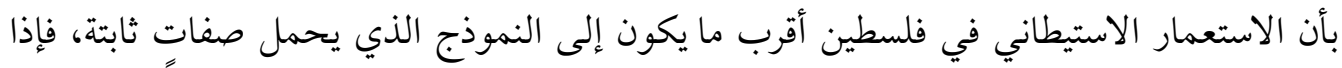

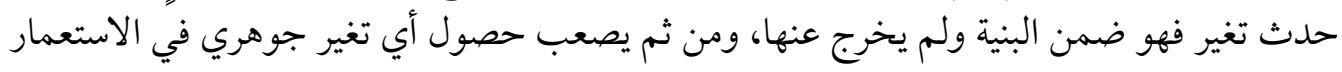

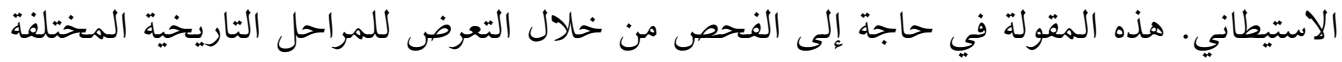

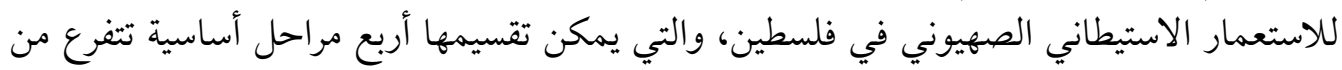

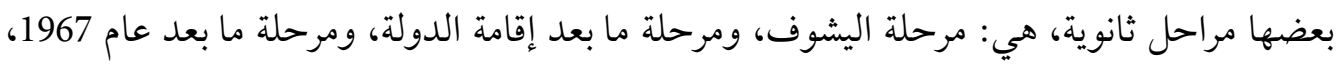

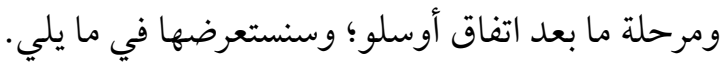

\section{1. مـرحلة اليشوف: مـن الاندماج إلى الغصل}

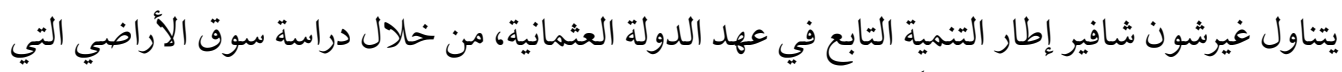

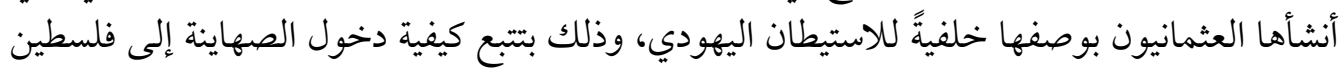

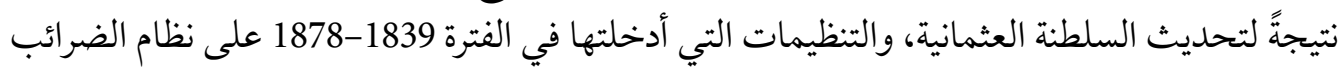

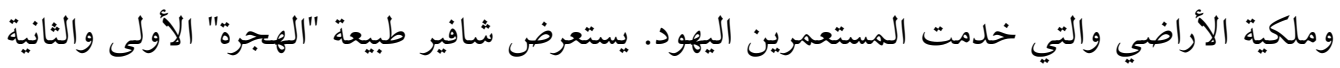

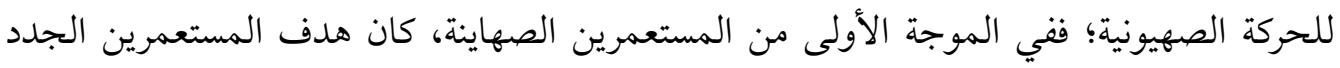

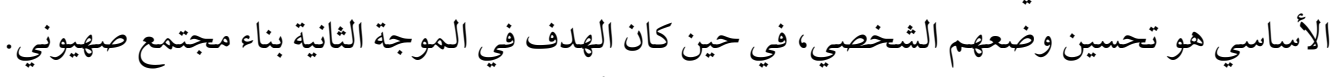

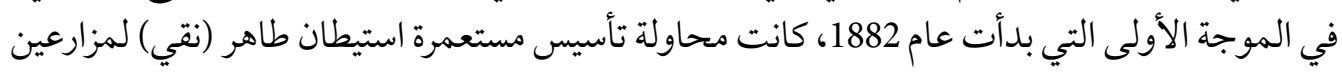

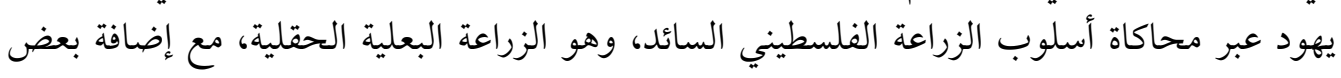

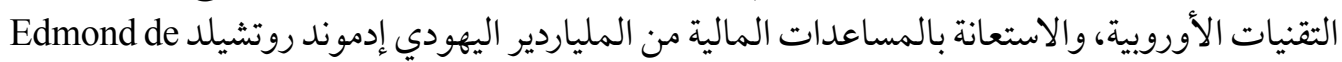

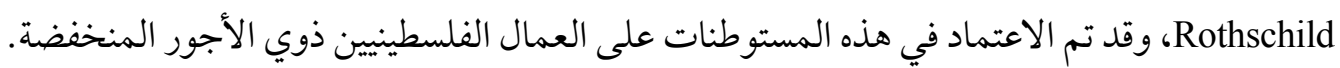

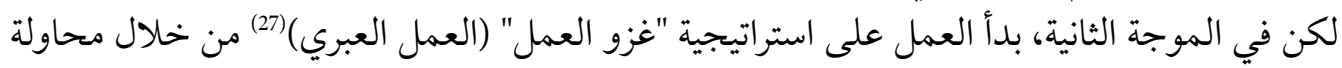

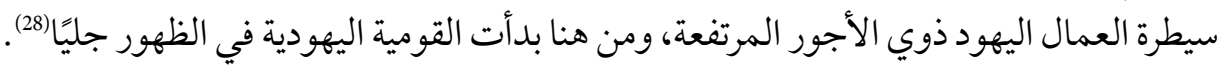

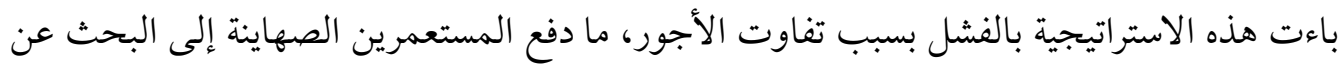

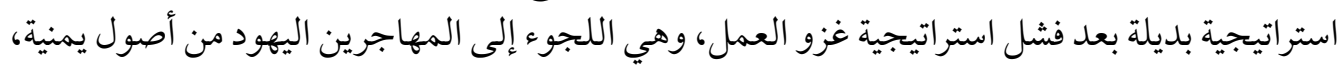

(26) Wolfe, "Settler Colonialism and the Elimination of the Native," p. 390.

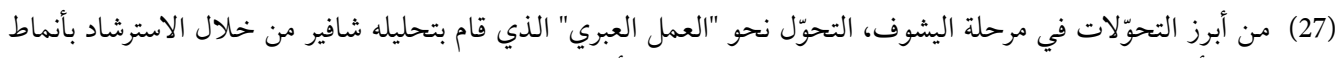

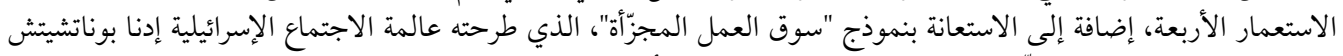
Edna Bonacich

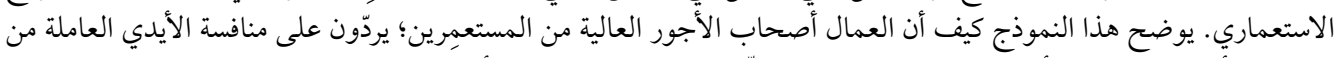

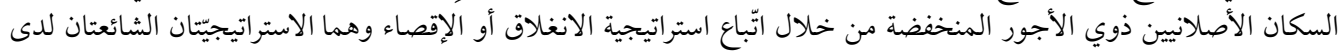

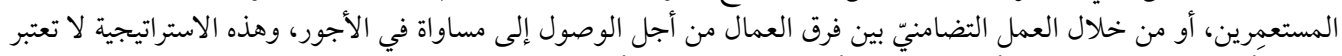

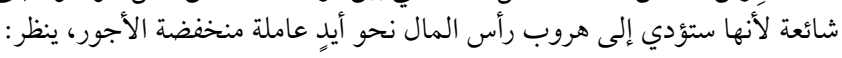
Gershon Shafir, Land, Labor and the Origins of the Israeli-Palestinian Conflict, 1882-1914 (Berkeley: University of California Press, 1996), p. 16.

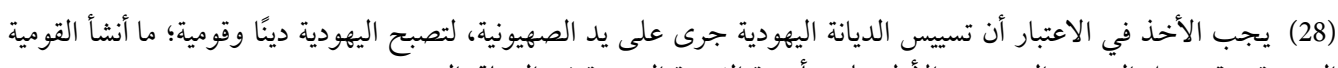

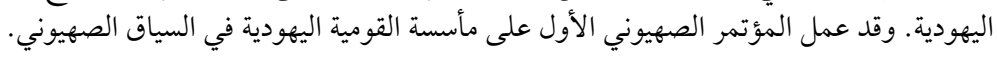




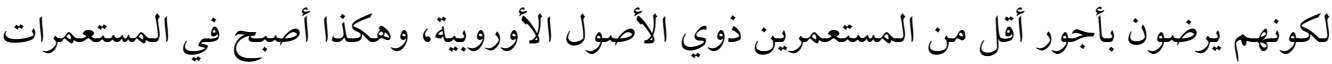

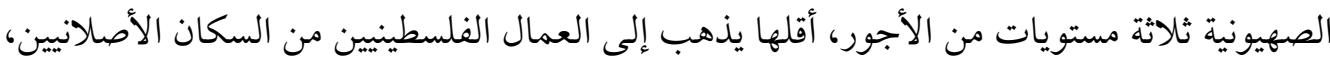

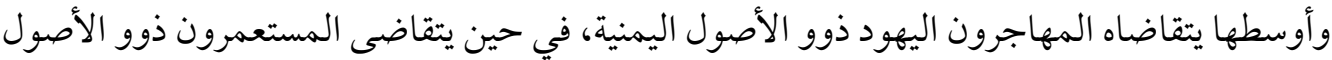

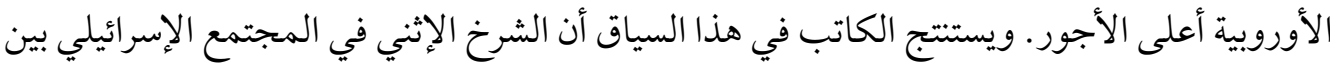

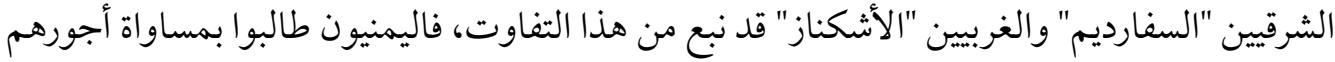

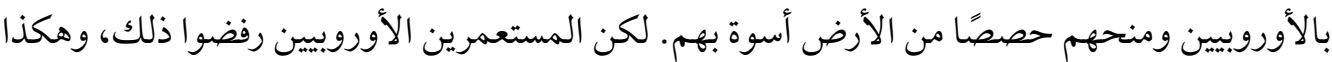

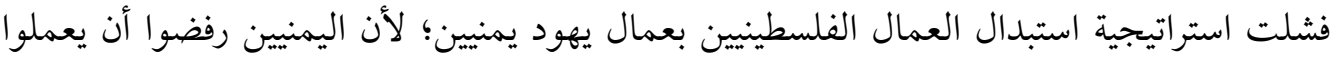
بأجور رخيصة وأن يكونوا عبيدًا لإخوانهم من المستعمرين اليهود الأوروبيين (29).

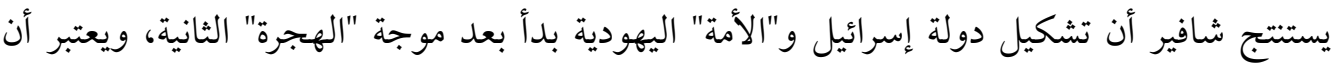

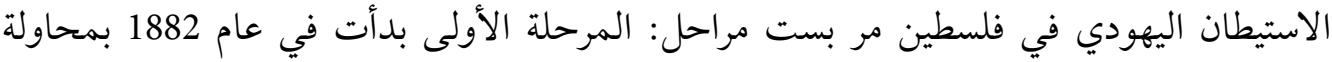

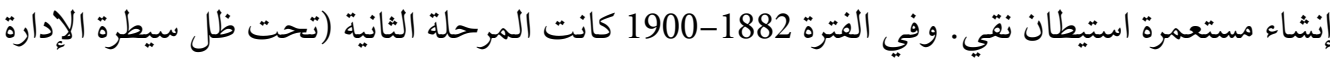

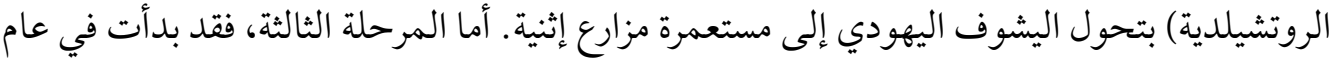

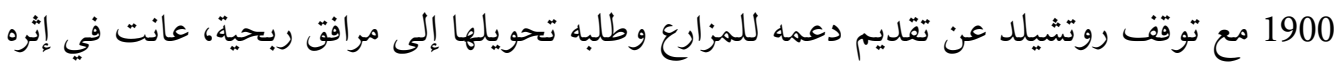

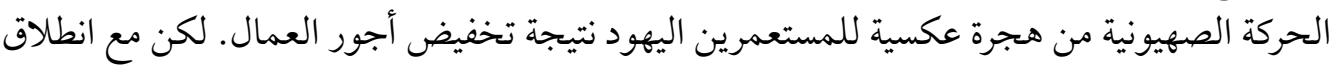

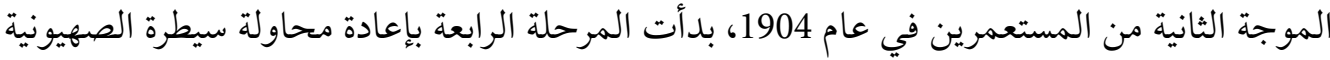

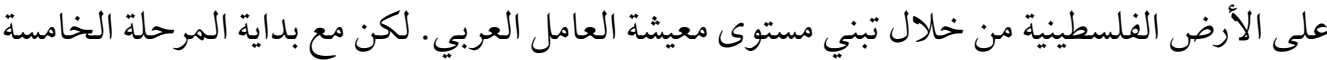

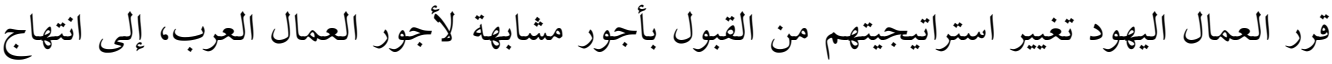

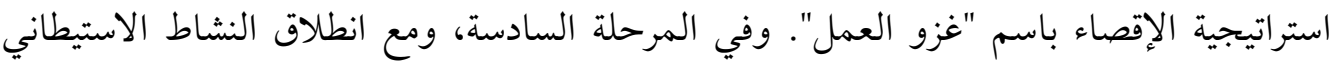

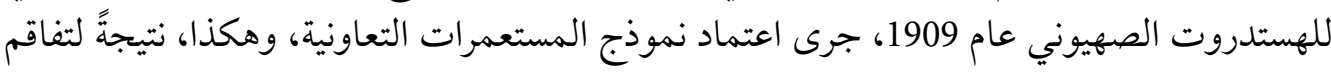

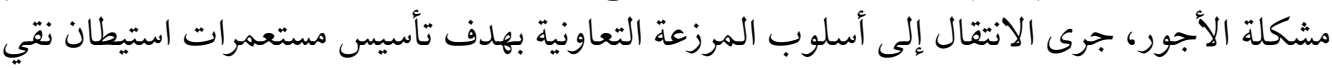
توفر أجورًا مقبولة للعمال من المستعمرين الأوروبيين (30).

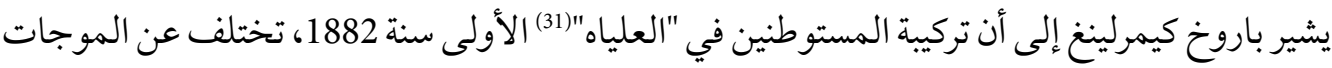

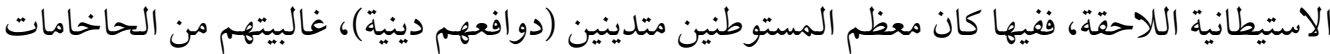

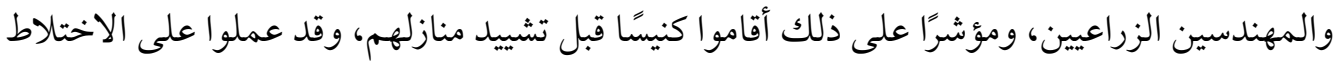

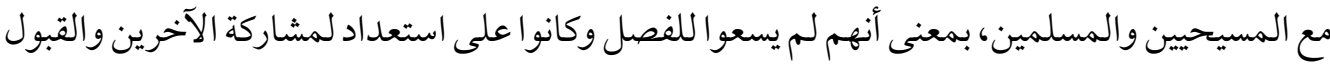

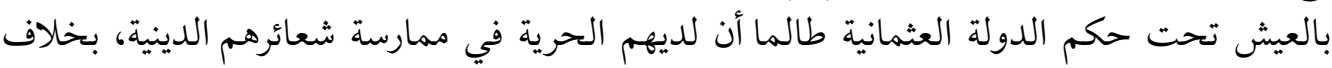

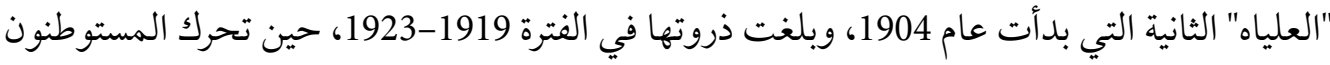
بدوافع سياسية أكثر من كونها دينية، وذلك بهدف تحقيق وبلفيق دروتها في الهوية القومية". وقد كان معظمهم من صغار

(29) Shafir, pp. 45-90.

(30) Ibid., pp. 187-220.

(31) مصطلح يستخدمه الصهاينة لتوصيف الهجرة الاستيطانة إلى فلسطين، ويعود في جذوره إلى أسس دينية، تفيد الحجّ إلى الى الهي 


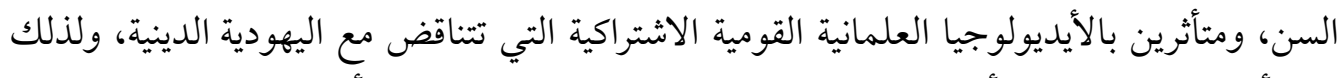

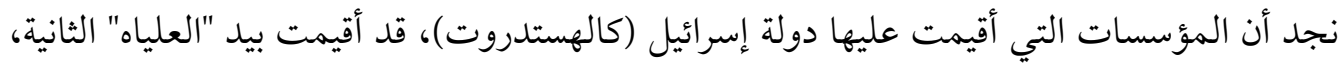

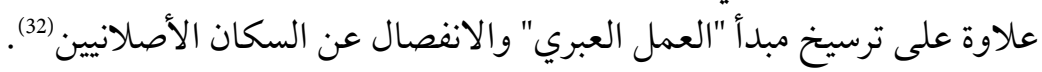

حصل تطور اقتصادي مزدوج منذ وصول الصهيونية إلى فلسطين في نهاية القرن التاسع عشر، تجسد

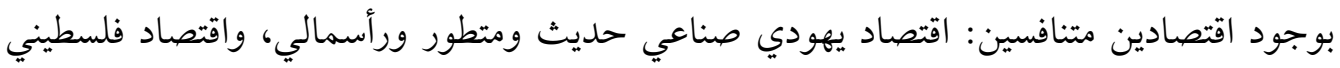

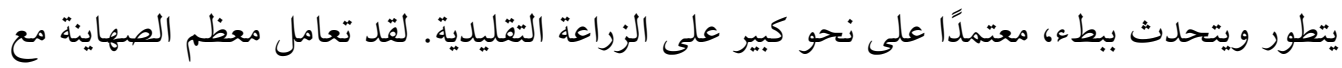

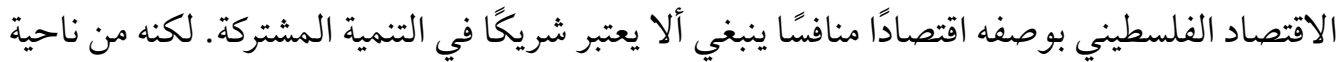

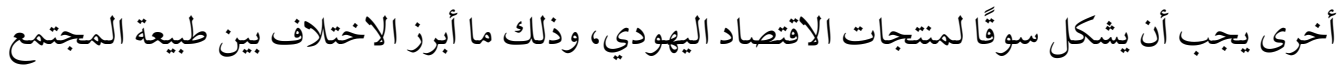

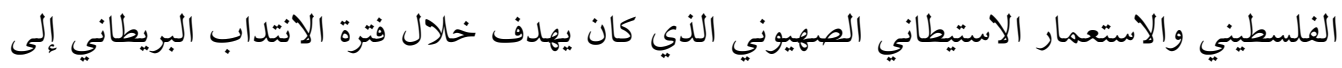

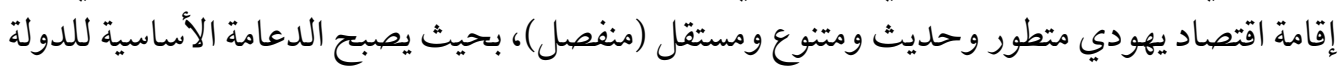
اليهودية التي سيتم إنشاؤها (33).

\section{2. ما بعد إقامة الدولة: المحو والنهـب والتذويب}

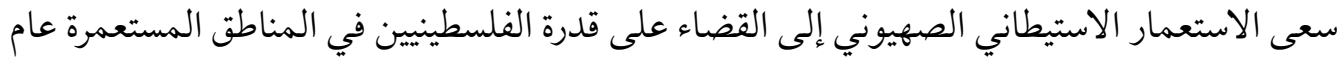

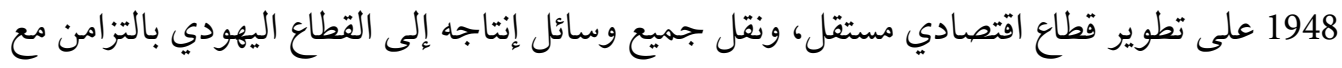

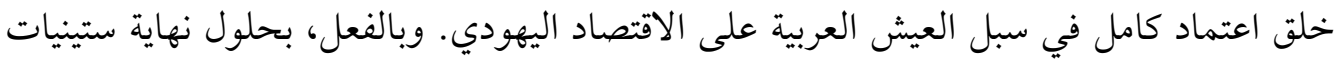

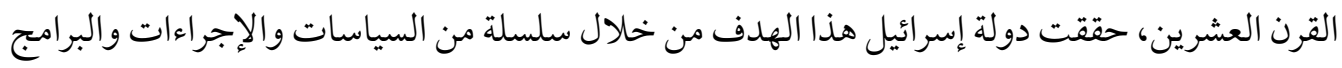

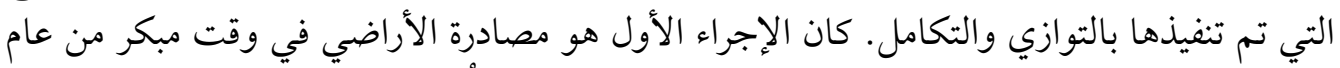

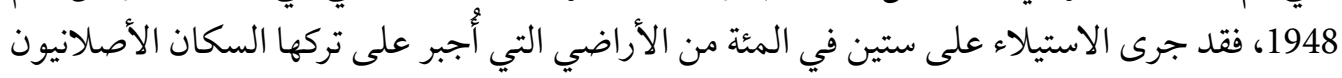

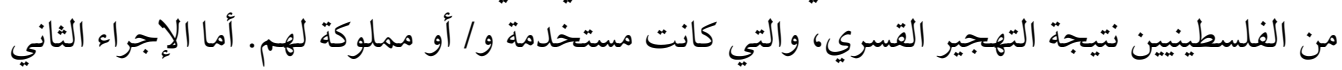

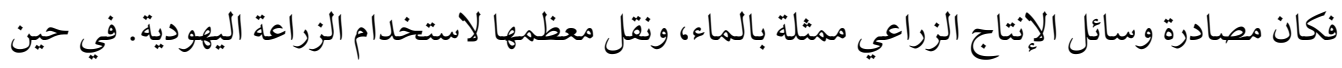

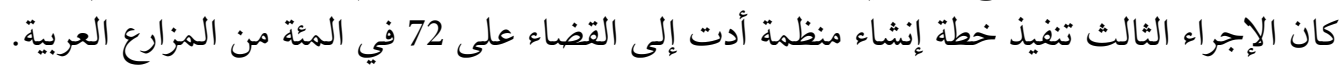

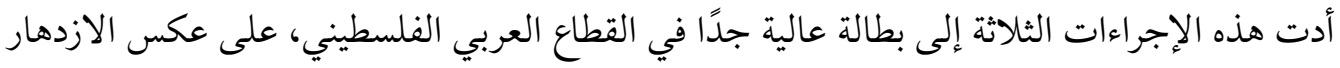

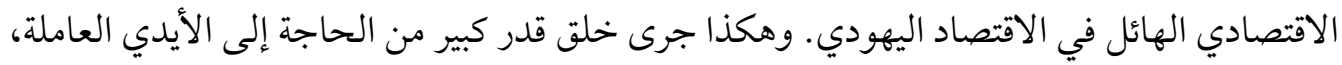

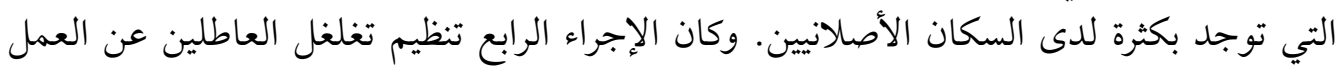

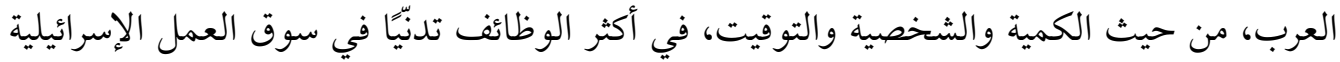

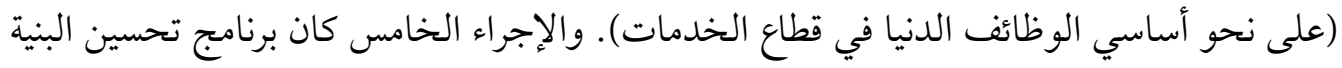

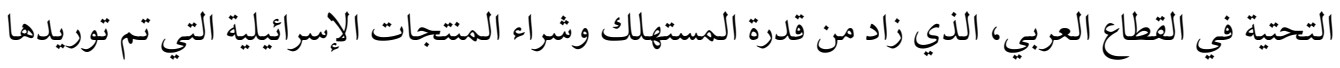

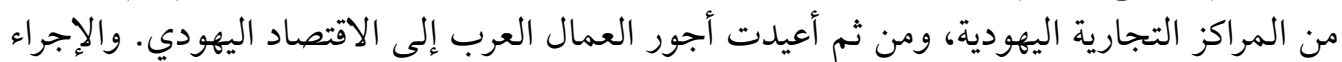

(32) Baruch Kimmerling, The Invention and Decline of Israeliness: State, Society and the Military (Berkeley: University of California Press, 2001), p. 193.

(33) يائير بوميل، "ربط الاقتصاد العربي بالقطاع اليهودي في إسرائيل، 1967-1988/2021/، موقع ترابط، 2011/2/6، شوهد في 
السادس كان منع التصنيع في القطاع العربي من أجل خلق اعتماد اقتصادي كامل للعرب على الاقتصاد اليهودي وإحباط إمكانية التنافس (34).

عقب الإعلان عن إقامة دولة إسرائيل، فُرض الحكم العسكري على السكان الفلسطينيين في المناطق المستعمرة عام 1948. واضطلعت عدة جهات بوضع السياسات، وفي مقدمتها لجنة سرية يطلق عليها "اللجنة المركزية للأمن"، (إضافة إلى "لجنة الشؤون العربية"(35) في حزب مباي(36)). في البداية، تركزت

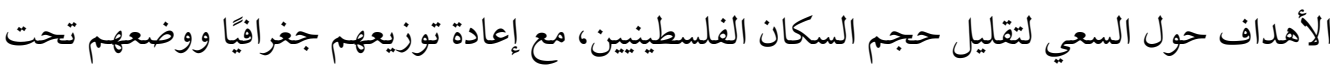
نظام مراقبة شديد (37).

وبحسب أحمد سعدي، بَنَت الحكومة الإسرائيلية سياساتها على اعتبار أن العرب المتبقين خطر أمني (طابور خامس)، ويقي ترحيلهم (على نحو مباشر) قائمًا حتى سنة 1959. غير أنه بدأ التحول في الموقف الإسرائيلي حينما دعا وزير الخارجية الإسرائيلي موشيه شاريت (في جلسة مغلقة لحزب مباي مائي سنة 1952) إلى "التهجير الهادئ" للعرب، مع تبني سياسة "الدمج" التدريجي للمتبقين. لكن وفي ضوء الفشل في ترحيلهم، اقترح إسحاق بن تسفي (الرئيس الإسرائيلي الثاني) التعامل مع الفلسطينيين من

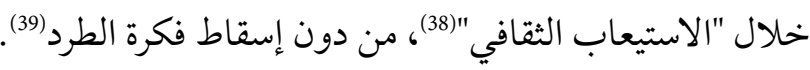

حدث تحول بنيوي في السياسات الإسرائيلية تجاه فلسطينيي الـ 48 في بداية عام 1957 ونهاية عام

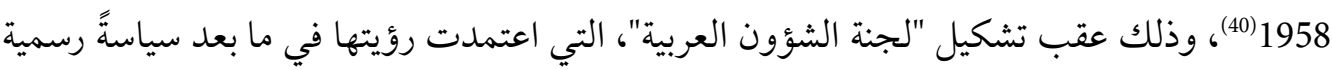
للحكومة الإسرائيلية(41). ونشأ التحول في إثر حدثين بارزين، هما الحرب على سيناء عام 1956 وما رافقها من احتلال قطاع غزة، بالتزامن مع مجزرة كفر قاسم (التي ارتقى فيها 49 شهيدًا). وقد فئد

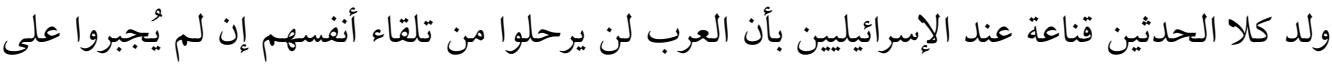
ذلك وتحدث لهم نكبة جديدة؛ وعلى الرغم من وقوع مجزرة كفر قاسم وحرب سيناء، فإنهم بقوا

(35) يائير بوميل، "أسس سياسات التمييز تجاه العرب في إسرائيل، 1948-1968"، نظرة في قيام إسرائيل، مج 16 (2006)، ص 393.

$$
\text { (36) حزب عمّال إسرائيل، وهو الحزب الحاكم في تلك الفترة. }
$$

(37) Tom Segev, 1949: The First Israelies (New York: An Owel Book, 1998), p. 52.

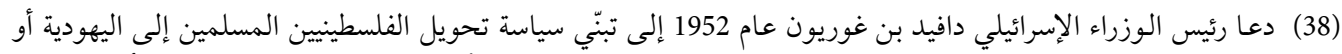

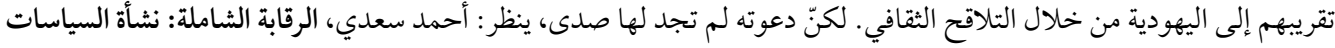

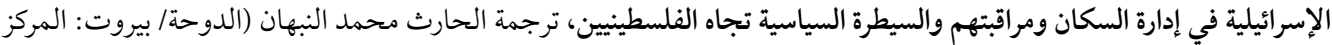

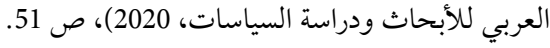

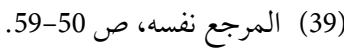

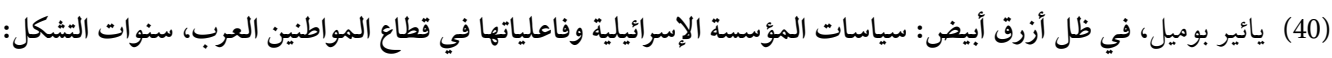

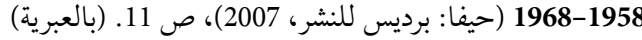
(41) Yair Bäuml, "MAPAI Committee for Arab Affairs: The Steering Committee for Construction of Establishment Policy towards Israeli Arabs, 1958-68," Middle Eastern Studies, vol. 47, no. 2 (March 2011), p. 413. 
صامدين على أرضهم، لذا يجب التخطيط على أساس استمرار وجود ما تبقى من الفلسطينيين (42).

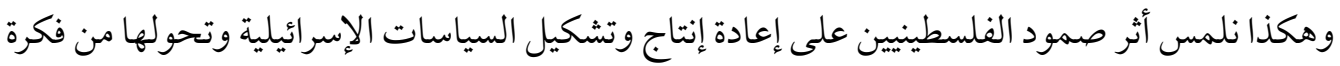

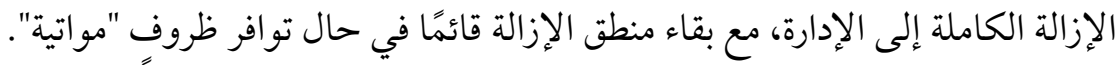

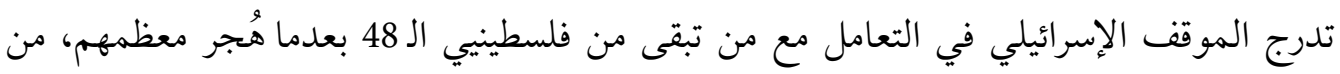

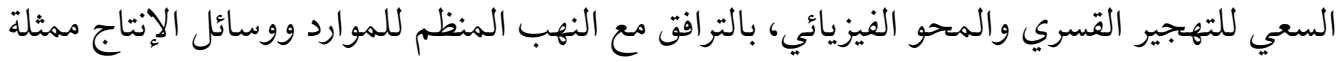

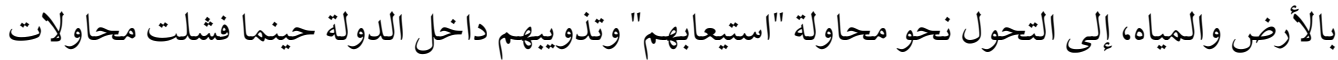
تهجيرهم العنيفة والهادئة.

تمظهر هذا التحول، في عام 1957، بتعويض المهجرين الداخليين، والاعتراف بالدروز بوصفهم أقلية،

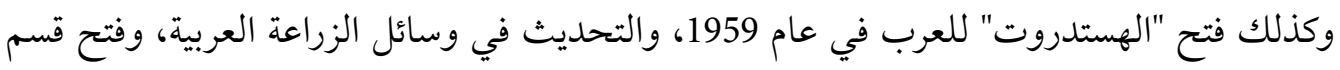
لتعليم العرب في وزارة التعليم، إضافة إلى ضم السلطات المحاملية العربية العبية إلى مركز السلطة المحلية (43).

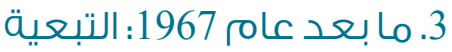

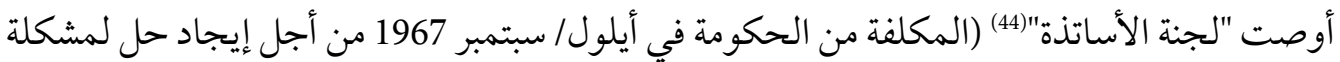

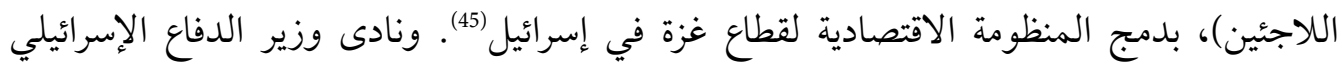

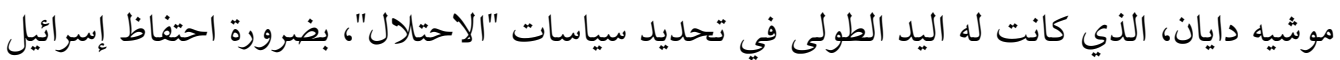

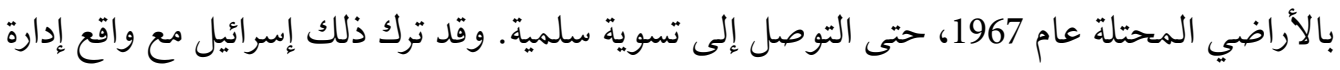

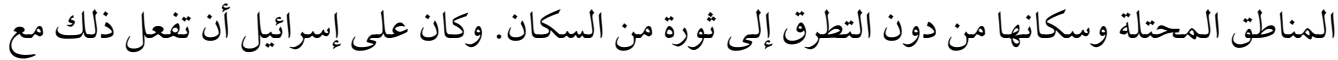

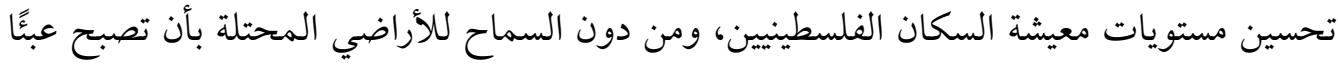

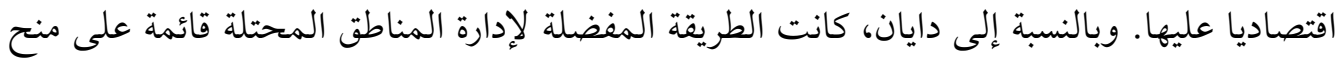

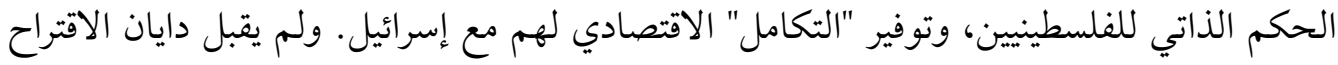

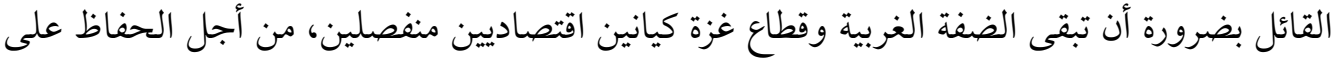
وضعهما بوصفهما ورقة مساومة (46).

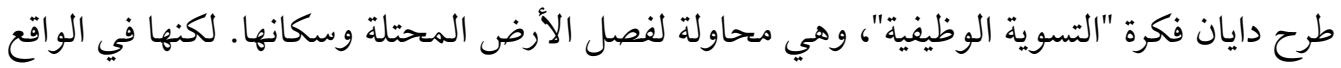

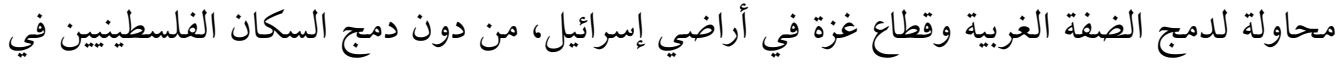

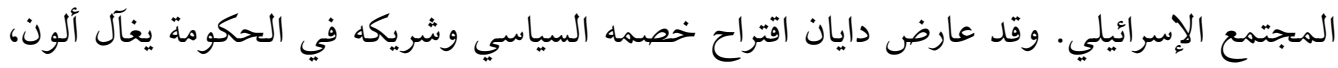

(42) Ibid., p. 414.

$$
\begin{aligned}
& \text { بوميل، في ظل أزرق أبيض، ص } 14 .
\end{aligned}
$$

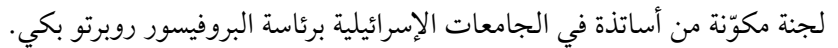

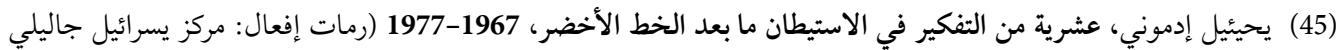

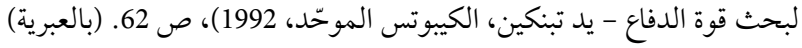
(46) Ronald Ranta, The Wasted Decade: Israel's Policies towards the Occupied Territories, 1967-1977 (London: London's Global University, 2009), p. 71. 


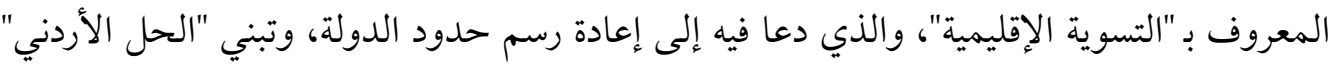

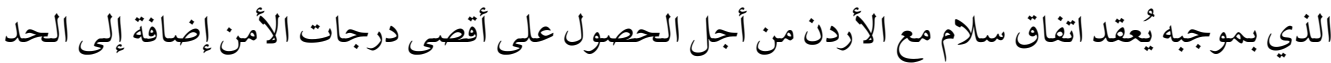

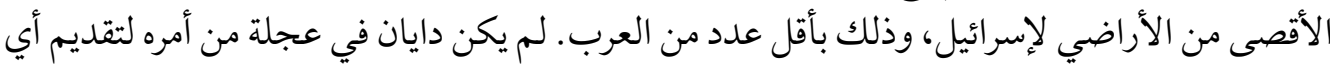

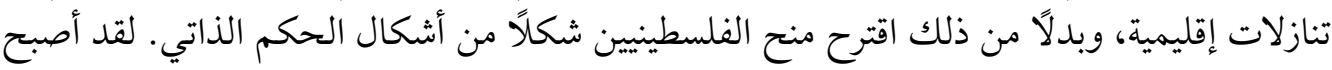

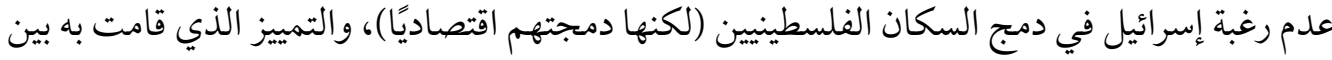

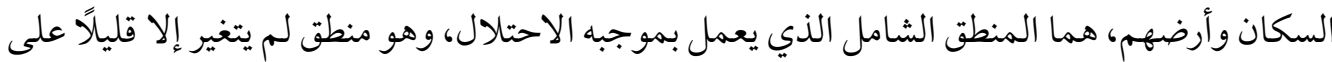
مر السنين، في حين تغير العديد من جوانب الحكم العسكري الإسرائيلي على نحو كبير (47). فُتح المجال أمام المتنافسَين الرئيسَين في الحكومة الإسرائيلية (دايان وألون) لوضع رؤيتيهما موضع

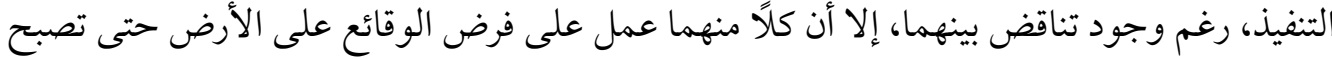

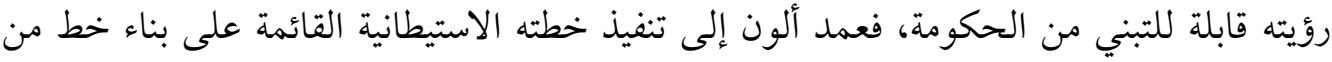

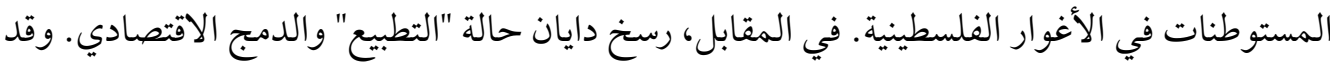

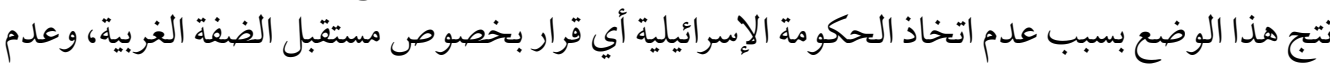
تبني خطة ألون أو دايان رسميًا

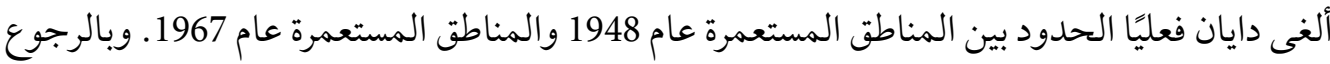
إلى جلسات لجنة المديرين العامين (49)، سنجد كيف جرى رائ ربط البنية التحتية المادية بين المنطقتين من خلال ربط شبكة الكهرباء والماء والاتصالات وحتى المواصلات. ولمئ ولم تكن معظم الرسوم الجمركية

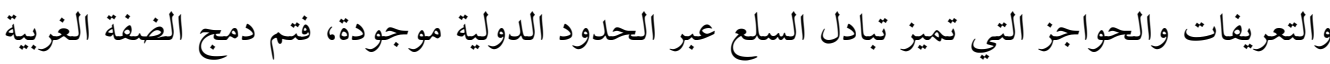
وقطاع غزة في اتحاد جمركي في إسرائيل ـ وعلاوة على ذلك، تم دمجهما في الاقتصاد الكلي الإسرائيلي

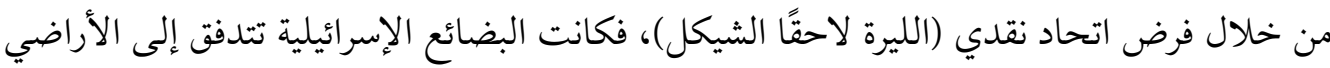

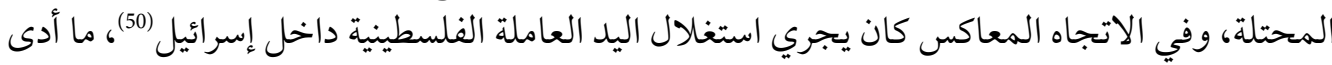
إلى تحويل فلسطين الانتدابية إلى وحدة اقتصادية واحدة.

يصف بابيه العلاقة الاقتصادية مع مناطق 1967 بـ "الاستعمار الاقتصادي الممنهج"(51)، في حين يشير غوردون إلى حدوث تحول في الأهداف "الوطنية" الإسرائيلية في ما يتعلق بالعمالة الفلسطينية بعد عام

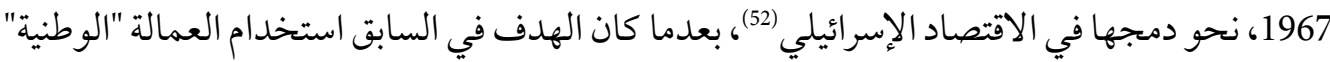

(47) Gordon, p. 6.

(48) ينظر : ليفي أشكول، رئيس الوزراء الثالث: شهادات مختارة من حياته (1895-1969)، أرشيف دولة إسرائيل (القدس: دار كيتر للنشر، (2001، صي 574.

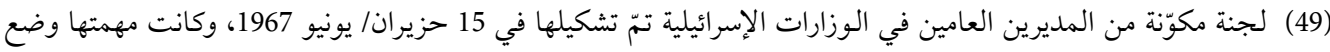

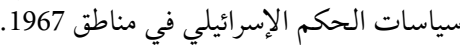

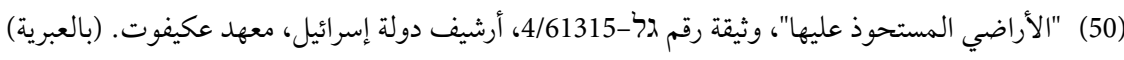
(51) Pappe, p. 147.

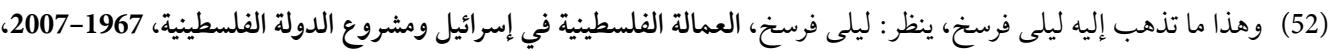

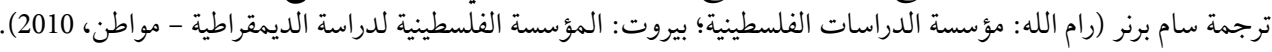


الإسرائيلية (53). ويجادل غوردون بأن ما يظهر بقوة عند فحص الأشكال المختلفة للسيطرة العاملة

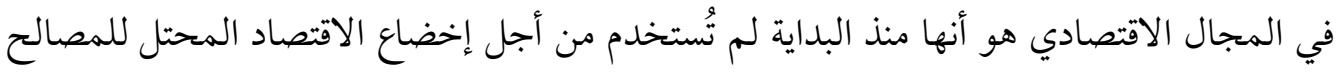

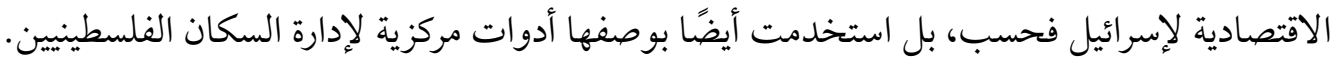

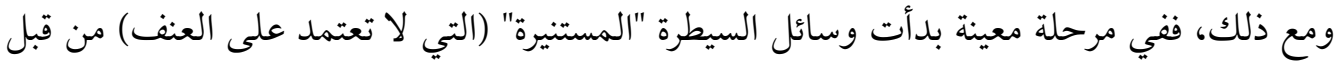

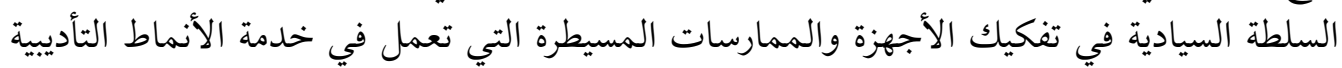
والبيولوجية للسلطة (54)، ما يجعل "الطابع الاستغلاكلي" للاحتلاكل وال مرئيًا (55). في المقابل، تجادل سارة روي Sara Roy بأن إسرائيل أنشأت بنية تحتية تلائم اقتصادها، لكنها لم

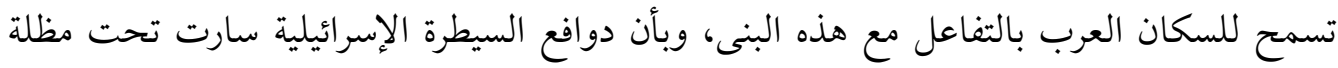

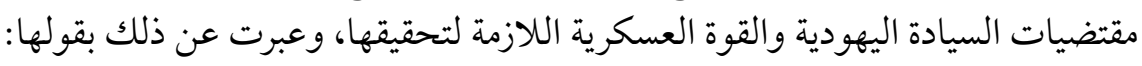

"لم تتعامل الصيغة الإسرائيلية الاستثنئية للاستعمار الاستيطاني مع قطاع غزة والضفة الغربية

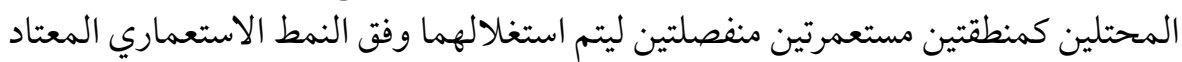

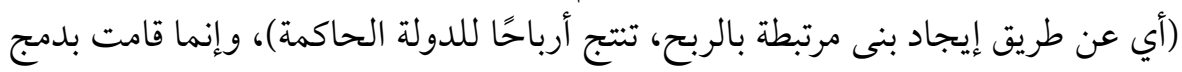

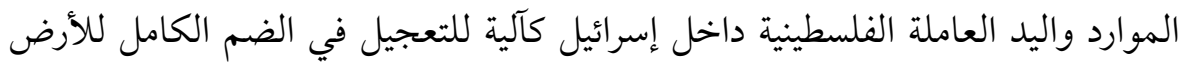

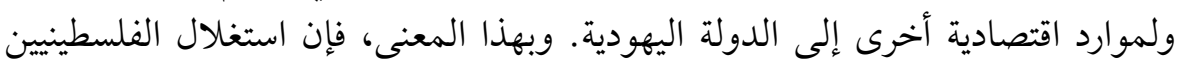

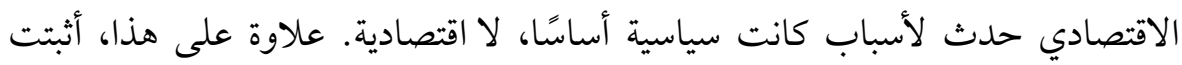

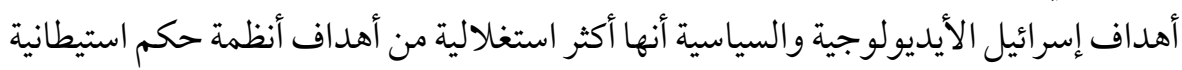

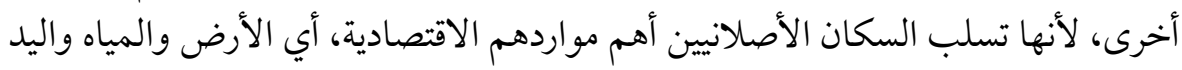

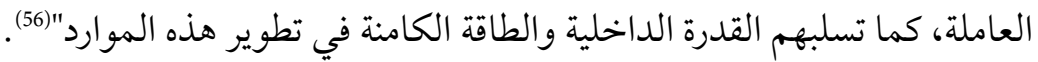

وتحاج روي بأن جوهر السياسة الاقتصادية التي اتبعتها إسرائيل في المناطق المحتلة قائم على الإفقار

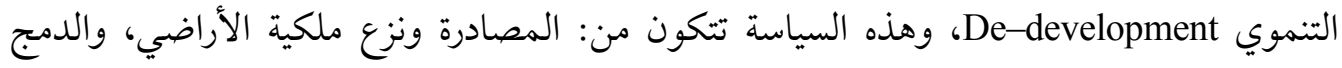

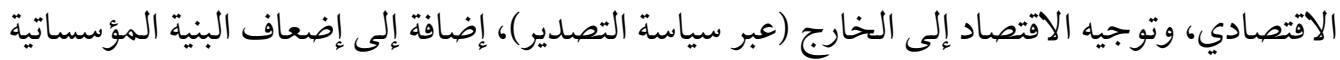

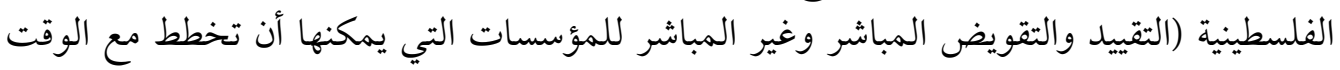

(53) Gordon, p. 76.

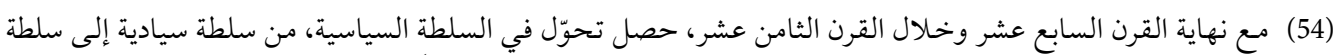

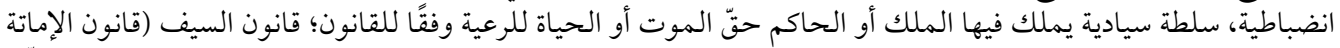

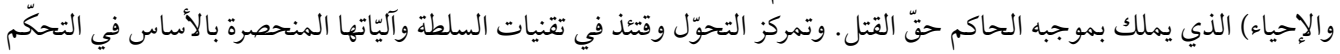

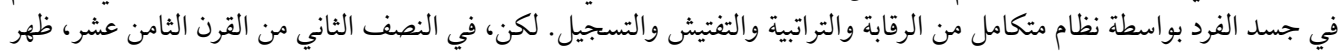

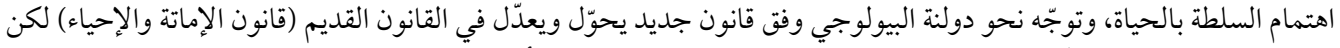

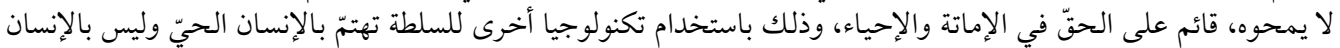

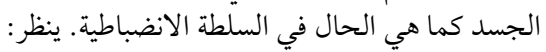

Michel Foucalute, Society must be Defended (New York: Picador, 2003), p. 241.

(55) Gordon, p. 76.

(56) سارة روي، قطاع غزة: السياسات الاقتصادية للإفقار التنموي، ترجمة محمد طربية (بيروت: مؤسسة الدراسات الفلسطينية، 
استثمارًا منتجًا وتدعمه) . وبناء عليه، فإن السياسة الاقتصادية استُخدمت بوصفها شكلًا من أشكال الرقابة

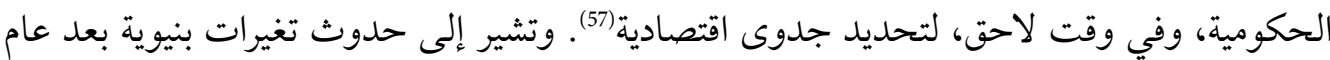
1967، إلا أنها كانت عبارة عن تغيير منحرف منع تحول النمو الإيجابي إلى تنمية اقتصادية طويلة الأمد (58).

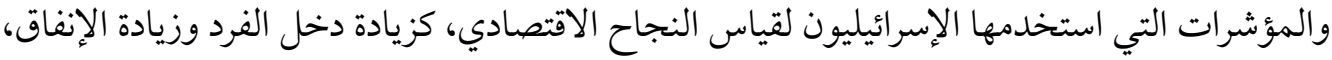
من أجل قياس النجاح الاقتصادي، تكشف فشل التشئ التهية الاقتصادية الحقيقية، فغياب التغيير البنيوي (الإيجابي) كان له تأثير تمثل بالتبعية الشديدة لإسرائيل، والتشظي في القطاعات، والتآكل الداخلي (59). يتمايز فيراشيني من وولف بادعائه وجود انقطاع في الاستعمار الاستيطاني بين عامي 1948 و1967،

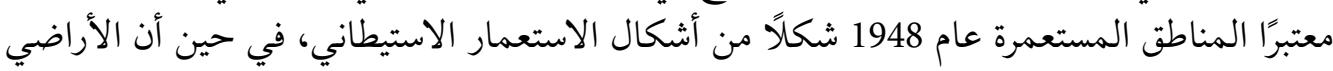
المحتلة في عام 1967 تمثل "فشلًا" للمشروع الاستعماري الاستيطاني الصهيوني؛ فالاستعمار

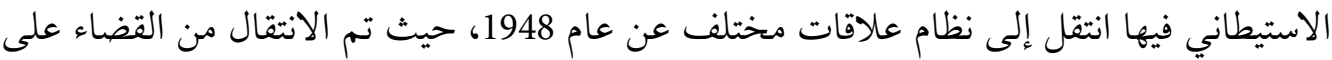

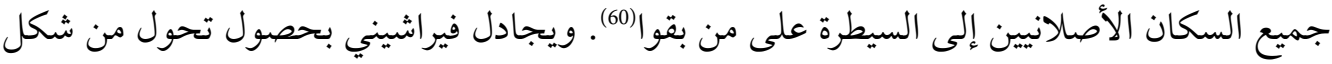

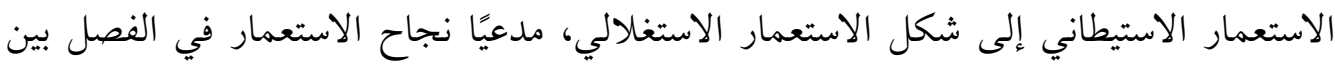

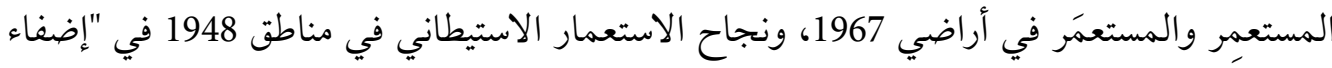

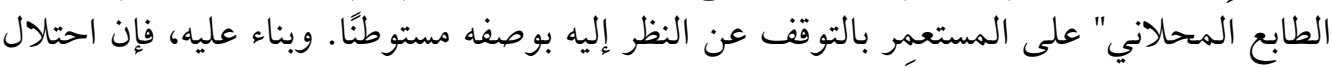

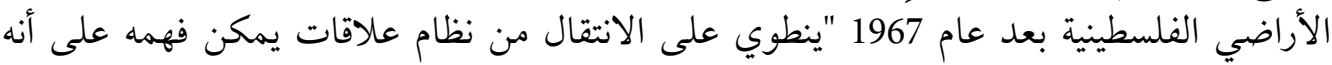

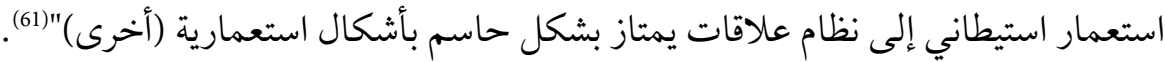

ويستند فيراشيني، في تمييزه بين نمطي الاستعمار (الاستغلالي والاستيطاني)، إلى كيفية التعامل مع

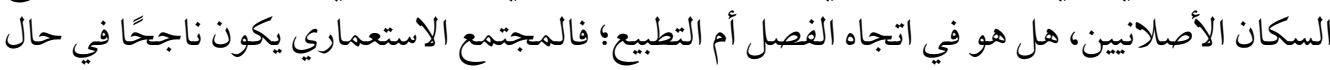

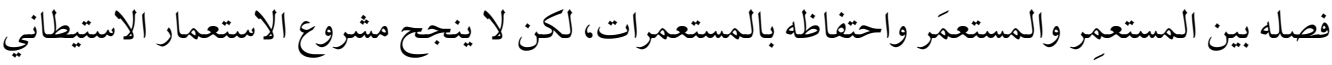

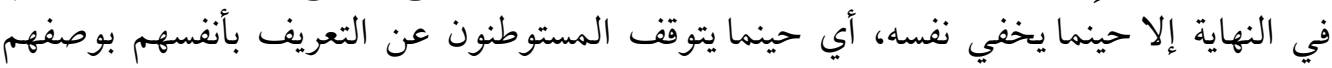

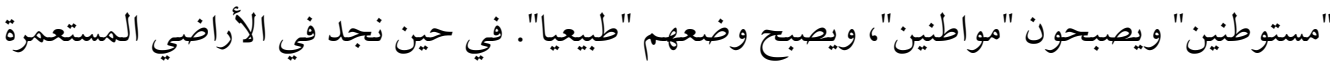

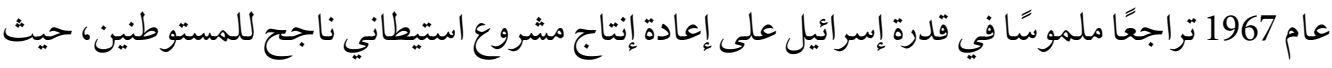

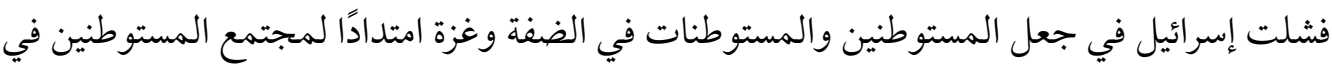

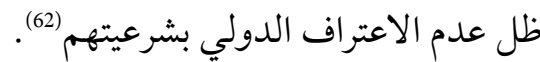

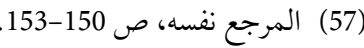

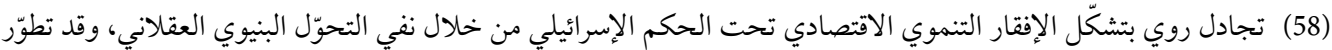

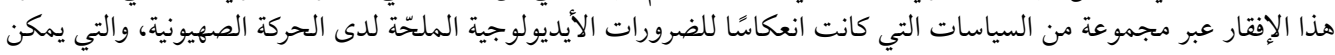

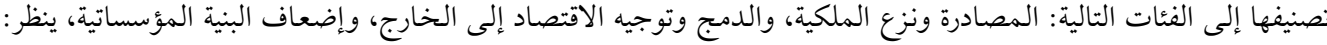
المرجع نفسه، ص صو 166. المرجع نفسه، ص 169.

(60) Lorenzo Veracini, "The Other Shift: Settler Colonialism, Israel and The Occupation," Journal of Palestine Studies, vol. 42, no. 2 (2013).

(61) Ibid., p. 27.

(62) Ibid., p. 28 


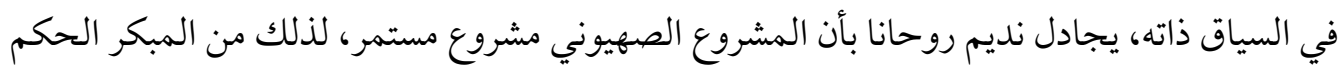

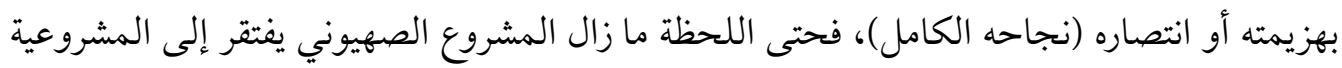

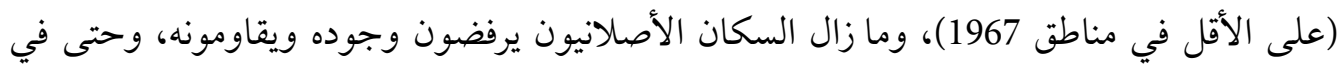

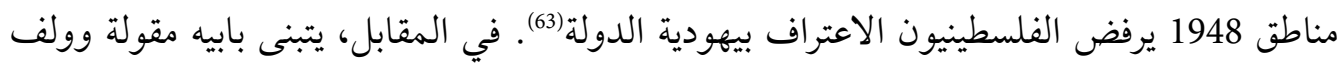

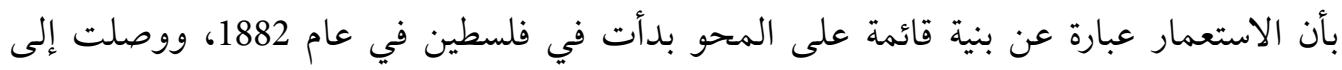

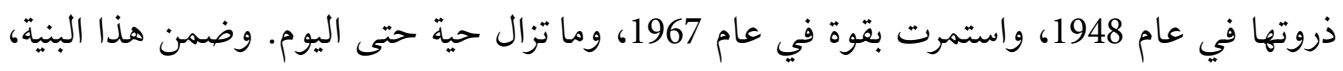

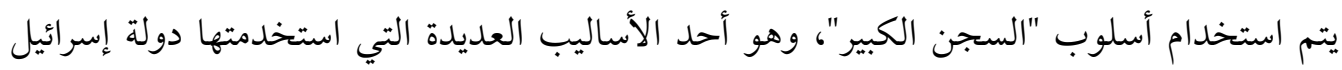

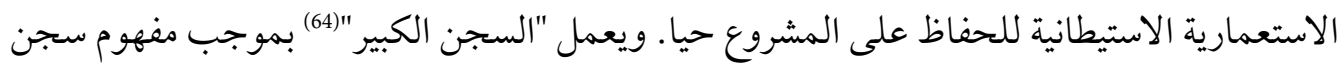

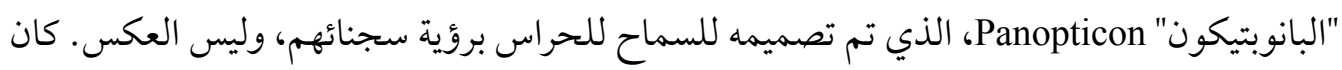

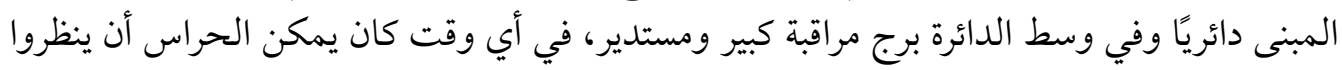

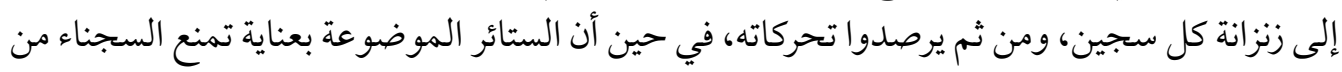

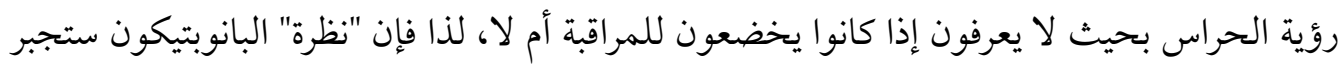

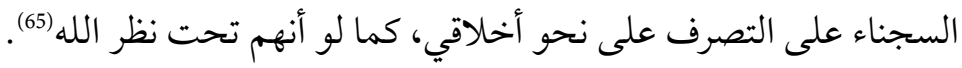

وبحسب بابيه، فإن إنشاء "السجن الكبير" في حزيران/ يونيو 1967 ليس من أجل الحفاظ على الاحتلال،

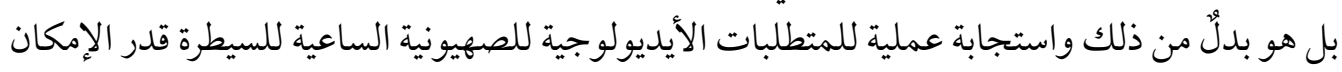

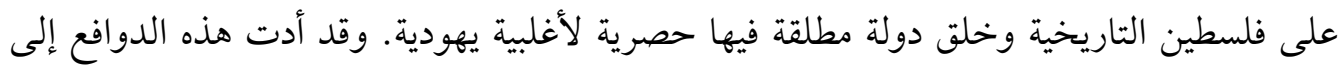

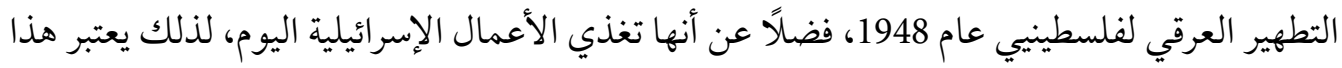

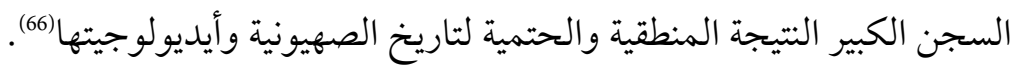

يحلل غوردون التحولات والتغيرات التي حدثت في عام 1967 باستخدام مفاهيم فوكو للسلطة، متخذًا

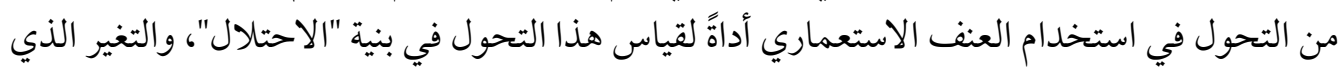

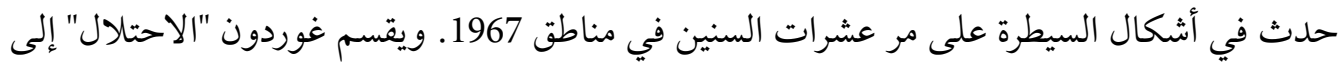

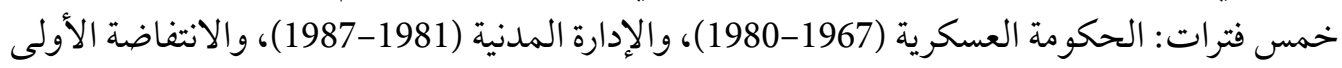

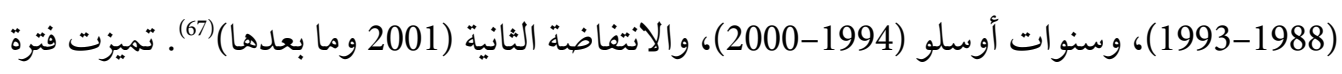

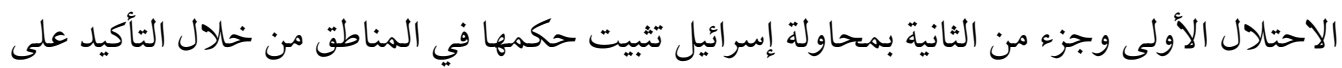

(63) نديم روحانا، "انتصار الصهيونية أو هزيمتها"، مجلة الدراسات الفلسطينية، العدد 110 (ربيع 2017)، ص 12-24.

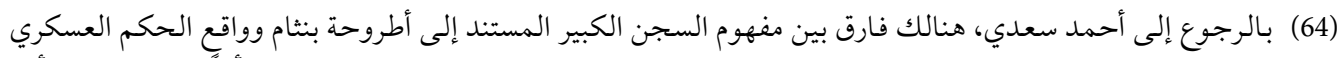

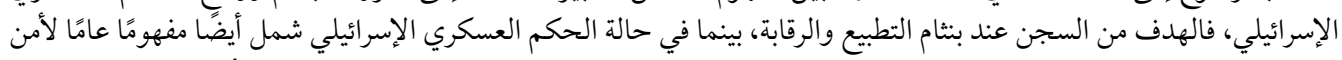

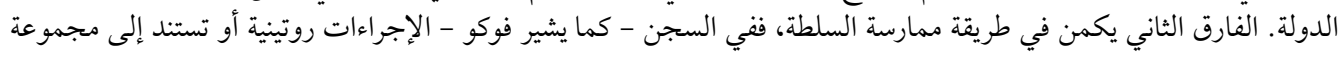

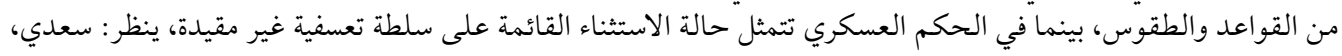

(65) Pappe, p. 3.

(66) Ibid., p. 4.

(67) Gordon, p. 18. 
أنماط السلطة التأديبية والبيولوجية، مع الأخذ في الاعتبار أنها استخدمت إجراءات قسرية ضد السكان

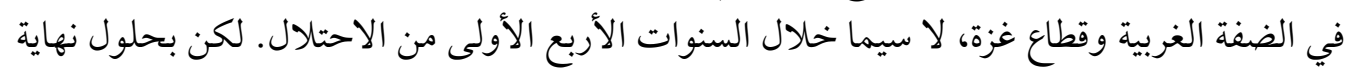
عام 1971، بعد أن نجحت إسرائيل في ضرب المقاومة المسلحة في غزة، تم تقليل استخدام القوة

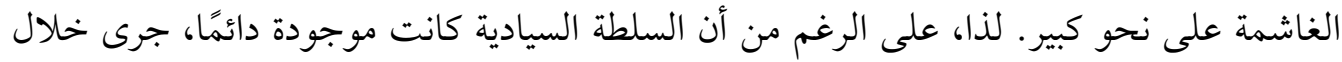

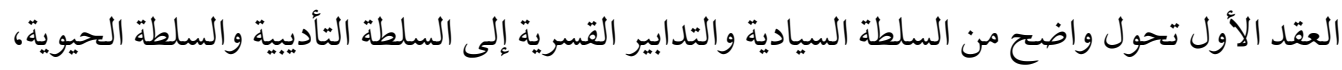
لكي يصبح السكان الواقعون تحت الاحتلال قابلين للانقياد ليس بسبب نشر القوات العسكرية بقدر ما هو بسبب رفع مستوى معيشتهم وتغيير نمط حياتهم (68).

\section{4. ما بعد اتغاق أوسلو : التبعية الاقتصادية مع الانغصال عن السكان}

أبرمت منظمة التحرير الفلسطينية مع إسرائيل ما يعرف باتفاق باريس الاقتصادي، وكان ملحقًا اقتصاديًا لاتفاق أوسلو. على أرض الواقع، وبحسب ما يشير غوردون، ساهم اتفاق باريس في تكرار العديد من الديناميكيات الاستعمارية التي كانت موجودة منذ عام 1967، فقد ضمن الاتفاق محافظة إسرائيل

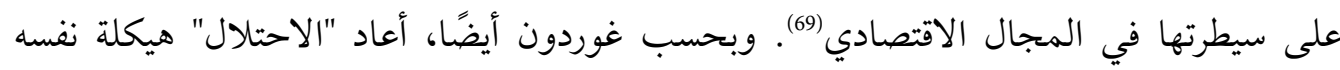
مع انطلاق الانتفاضة الأولى، فقلل من التركيز على الأنماط التأديبية والحيوية للسلطة مع التأكيد

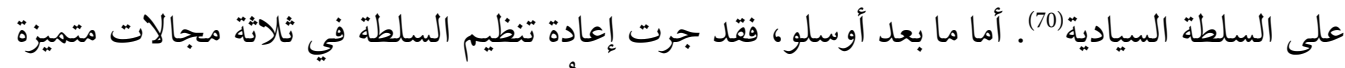

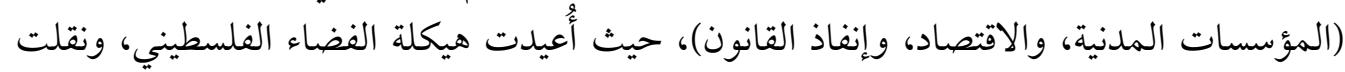

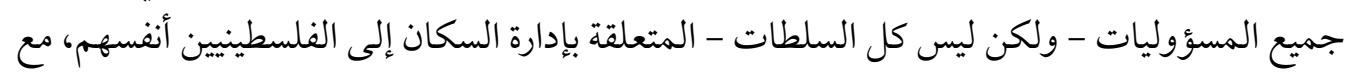
محافظة الاحتلال على سيطرته المتعلقة بالفضاء الفلسطيني (71). تحول "الاحتلال" نحو تبني مبدأ الفصل الكلّي على حساب مبدأ الاستعمار، الذي يعني محاولة إدارة

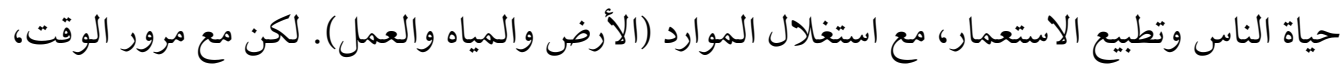

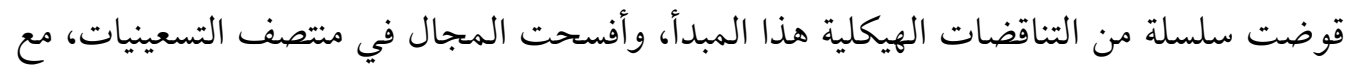
إبرام اتفاق أوسلو، لمبدأ إرشادي آخر هو مبدأ الفصل، والمقصود به التخلي عن الجهود المبذولة

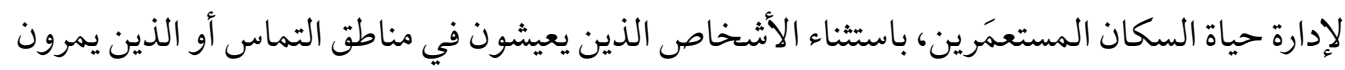
عبر نقاط التفتيش، مع الإصرار على استمرار استغلال الموارد غير البشرية (الأرض والمياه). إن عدم النماه

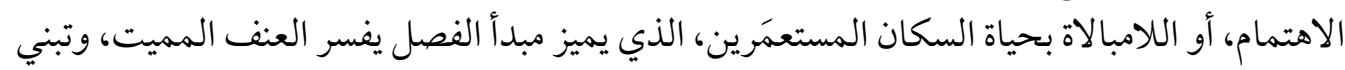

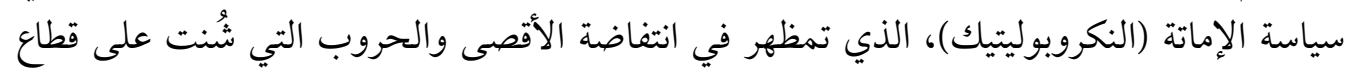

(68) Ibid., p. 50.

(69) Ibid., p. 174.

(70) Ibid., p. 158.

(71) Ibid., p. 173.

(72) Ibid., p. 200. 
يمكننا القول، بالاستناد إلى ما سبق، إن هنالك تغيرًا وتحولًا في الاقتصاد السياسي للاستعمار

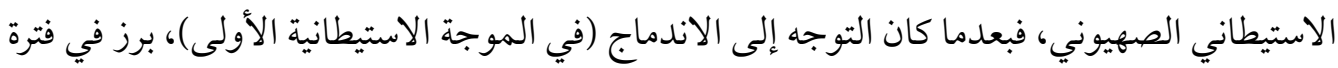

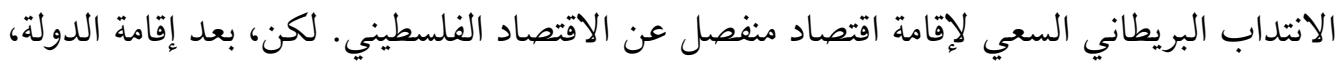
تحول نحو نهب الاقتصاد الفلسطيني في مناطق 1948 وتذويبه في الاقتصاد الإسرائيلي واستغلاليال

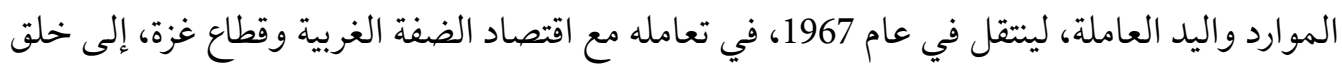

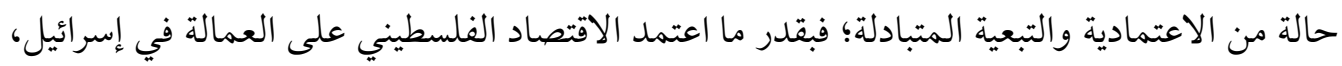

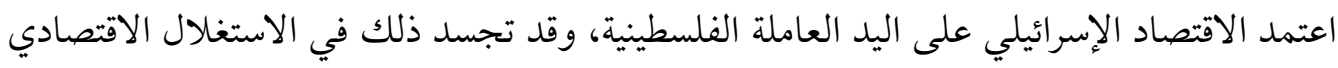

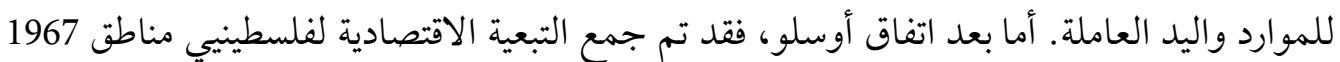

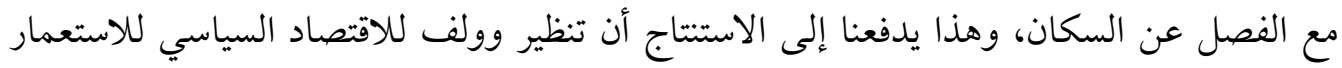

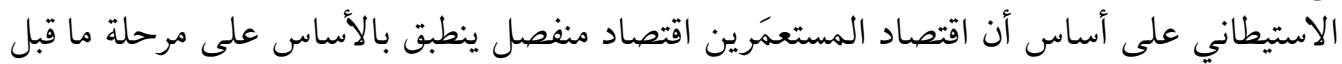

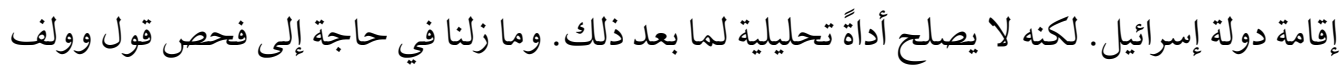

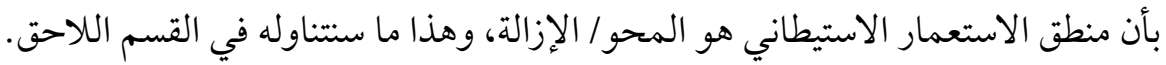

\section{ثنانيًا: العنف الاستعماري: محو وتطهير عرقي أهم تحكمر وضبط وسيطرة؟}

نظر زئيف جابوتنسكي Ze'ev Jabotinsky (1880-1940) إلى استخدام العنف في السياق الاستعماري

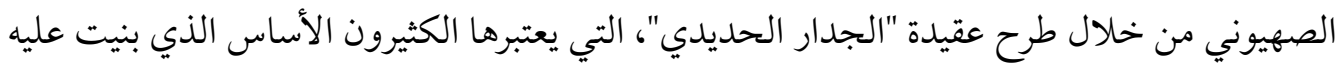

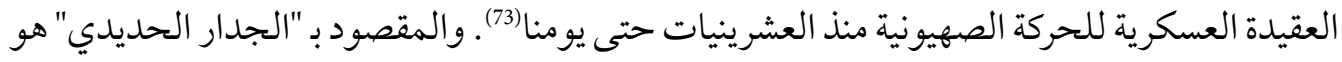

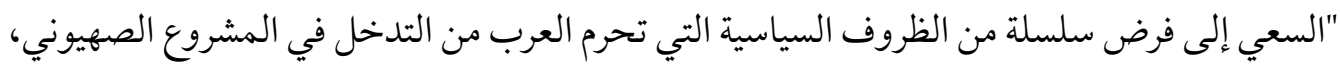

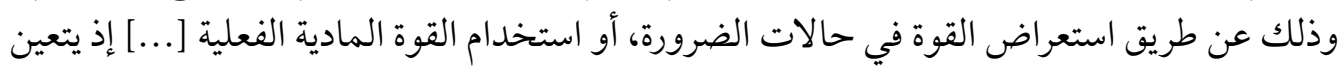

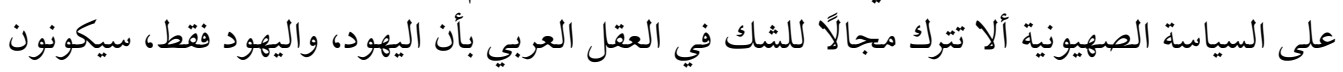

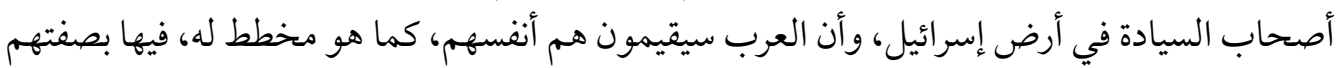
أقلية قومية" (74).

يشير وولف إلى أن المستعمرين في الاستعمار الاستيطاني يأتون بنية البقاء (75)، ويجادل بأنه مرتبط

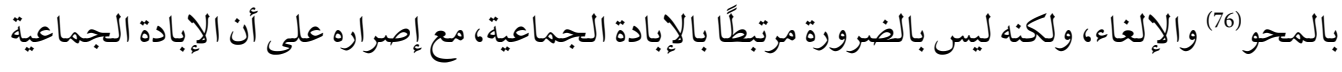

(73) نبيه بشير، "قراءة جديدة لعقيدة الجدار الحديدي: مرفق نص: النظرية الأخلاقية للجدار الحقيقي"، مجلة قضايا إسرائيلية، العدد 69 (2018)، ص 40.

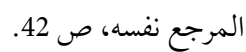

(75) Wolfe, Settler Colonialism and the Transformation of Anthropology, p. 2.

(76) المقصود هنا المحو الديموغرافي بمعنى الترحيل القسري للأصلانيين خارج حدود الكيان الاستعماري، فقد توسع بعض

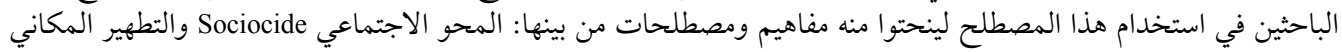

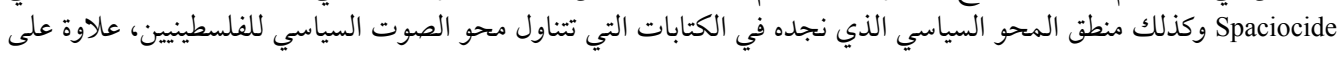

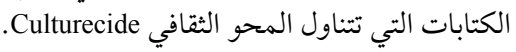




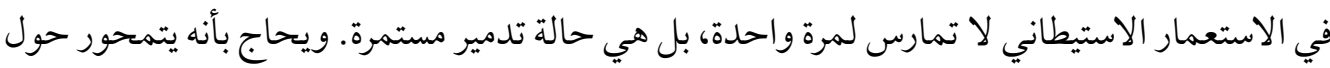

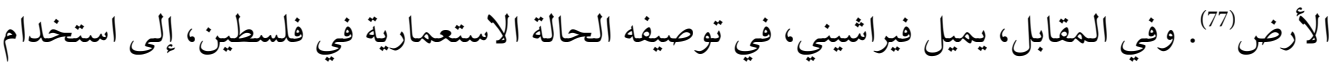
مصطلح الترحيل Transfer بدل الإزالة والمحو (78).

أما بابيه فيعتبر أن العدسة المناسبة لدراسة الاستعمار الاستيطاني الصهيوني هي التطهير العرقي،

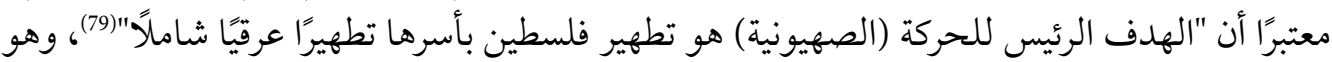

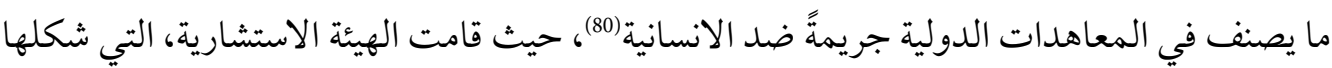

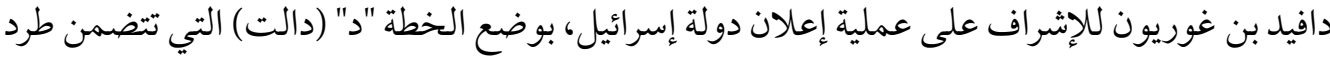

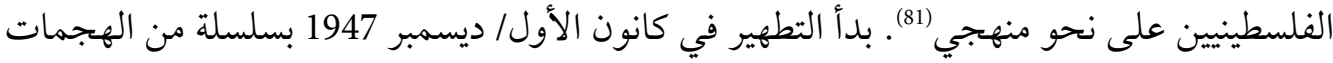

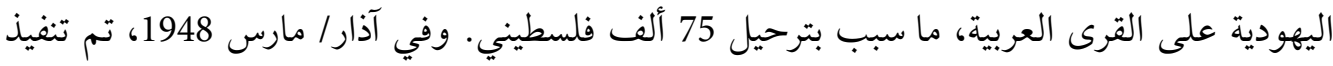

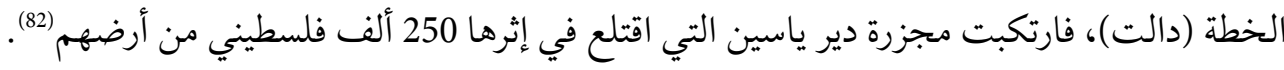
يشير بابيه إلى حدوث 31 مجزرة في المناطق المستعمرة عام 1948، في الفترة 11 كانون الأول/

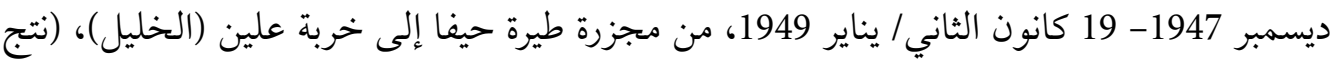

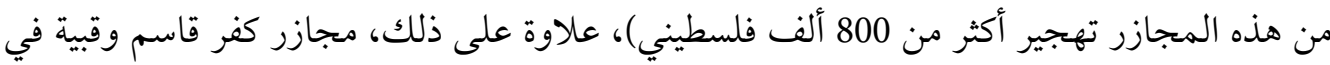
الخمسينيات، والسموع في الستينيات (83). أما في المناطق المستعمرة عام 1967، فقد تم استبعاد التطهير العرقي على نطاق واسع بسبب الظروف

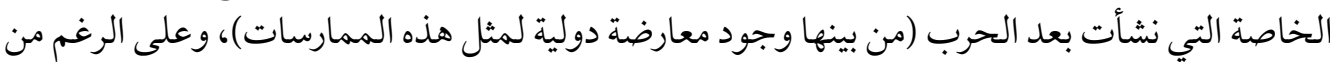

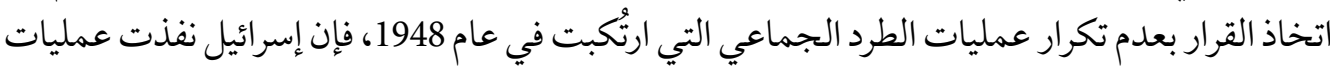

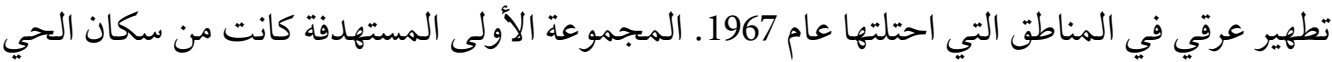

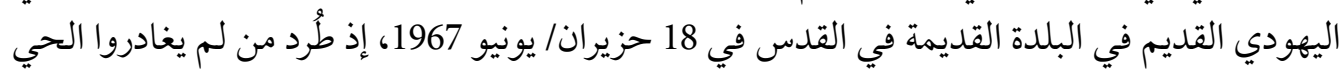

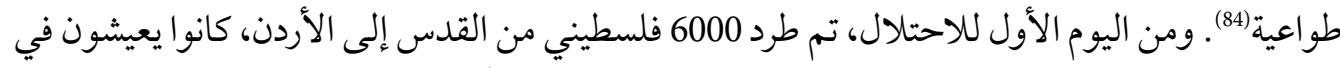

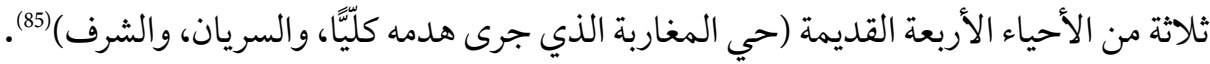

يظهر أرشيف الأمم المتحدة خمس حالات من التهجير وهدم البيوت في مناطق الضفة الغربية:

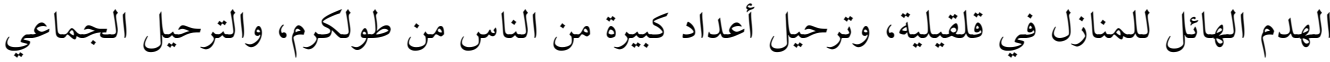

(77) Wolfe, "Settler Colonialism and the Elimination of the Native."

(78) Lorenzo Veracini, Settler Colonialism: A Theoretical Overview (Basingstoke: Palgrave Macmillan, 2010).

(79) إيلان بابيه، التطهير العرقي في فلسطين، ترجمة أحمد خليفة (بيروت: مؤسسة الدراسات الفلسطينية، 2007)، ص 7.

$$
\begin{aligned}
& \text { (80) المرجع نفسه، ص } 12 . \\
& \text { (81) المرجع نفسه، ص } 37 . \\
& \text { المرجع نفسه، ص صل } 50 . \\
& \text { المرجع نفسه، ص } 288 .
\end{aligned}
$$

(84) Pappe, p. 112.

(85) Ibid., p. 82. 


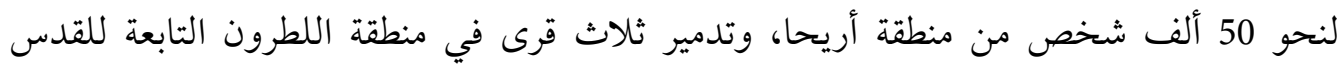

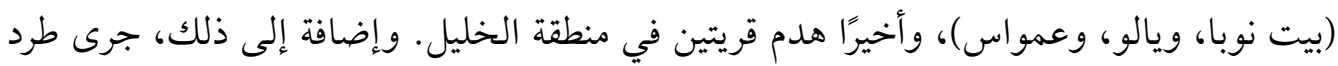

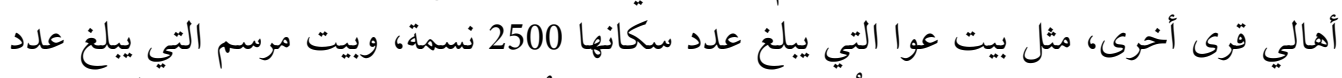

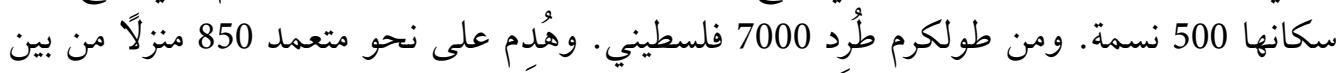

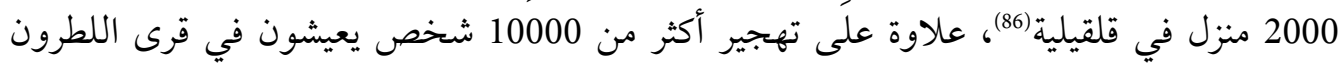

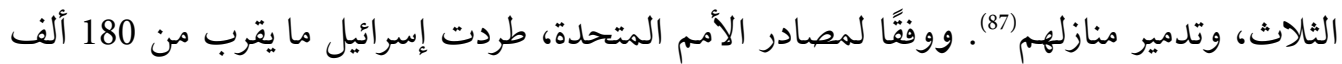

$$
\text { فلسطيني في الأيام الأولى للاحتلال (88). }
$$

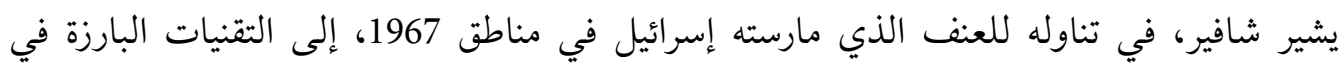

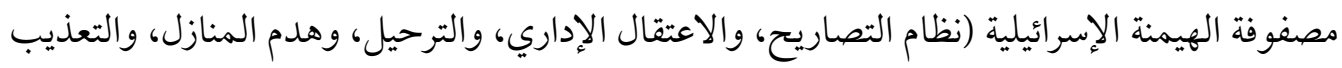

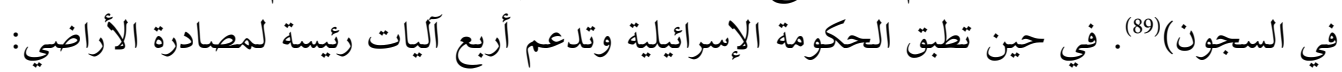

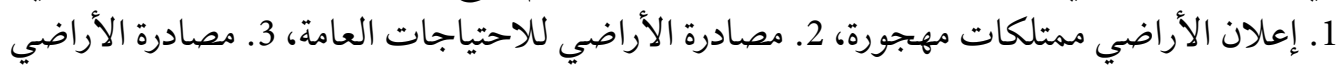

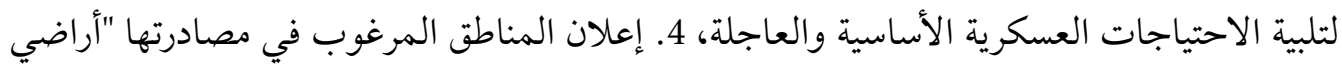

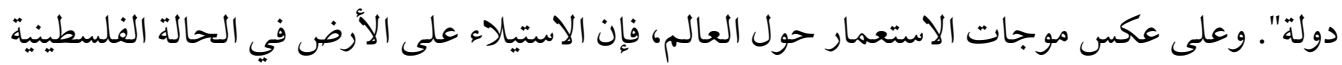

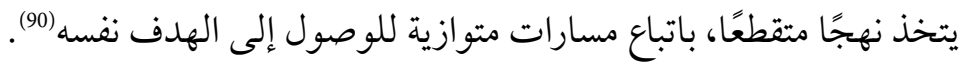

يحاول غوردون، في تناوله العنف الاستعماري الإسرائيلي في مناطق 1967، تفسير (91) العدد القليل

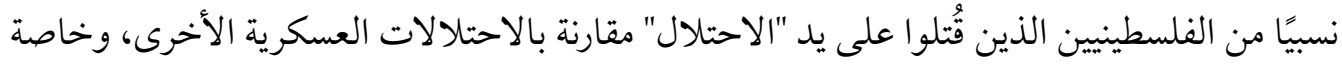

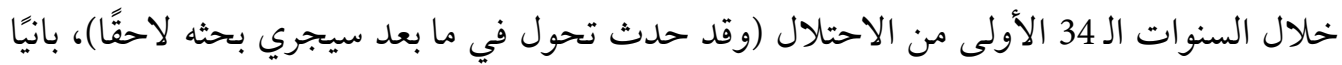

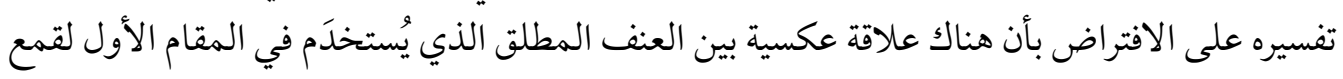

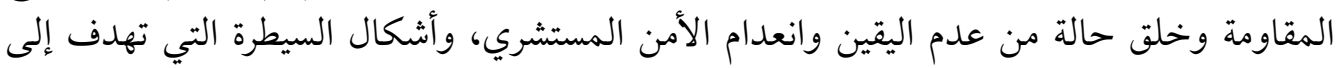

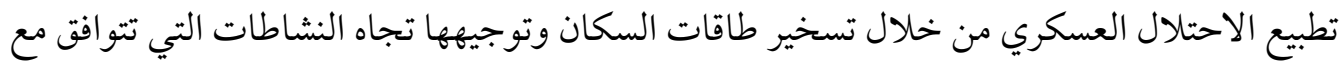

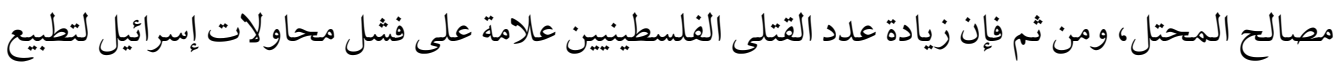

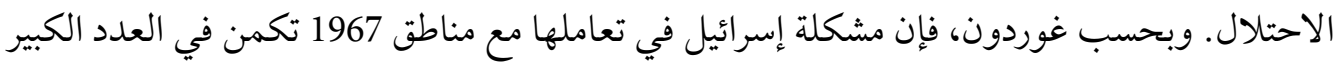

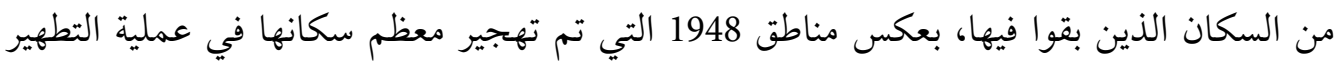

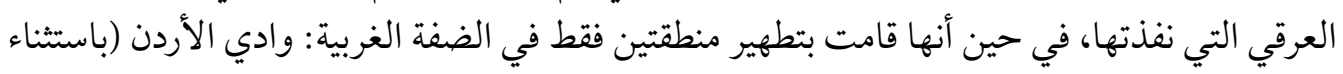

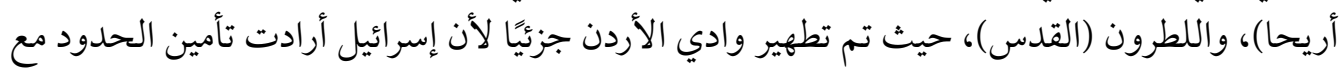

(86) Ibid., p. 116.

(87) Ibid., p. 119.

(88) Ibid., p. 127.

(89) Gershon Shafir, A Half Century of Occupation (Berkeley: University of California Press, 2017), p. 35.

(90) Ibid., p. 71.

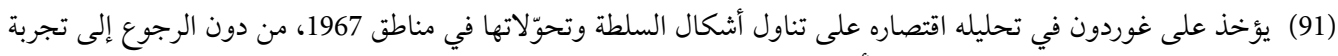

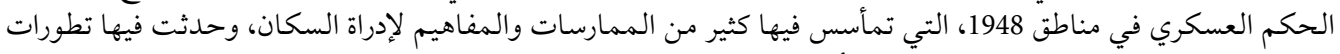
وتحولات مهمة في كيفية التعامل مع السكان الأصلانيين. 
الأردن، كما تم إخلاء جيب اللطرون من السكان(92). (يغفل غوردون عن التهجير الذي حصل في باقي مناطق الضفة، كقلقيلية وطولكرم وبيت عوا التي أشار إليها بابيه). ويفسر غوردون عدد القتلى القليل نسبيًا من الفلسطينيين بالاستناد إلى مفاهيم فوكو للقوة وأشكال السيطرة،

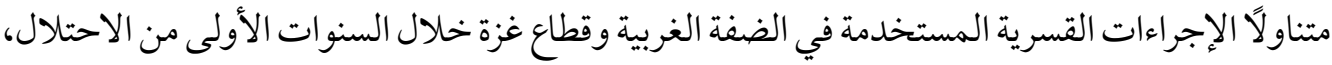

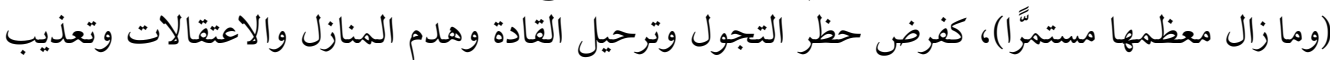

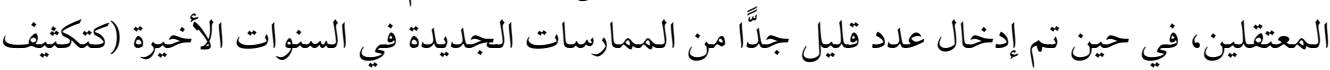

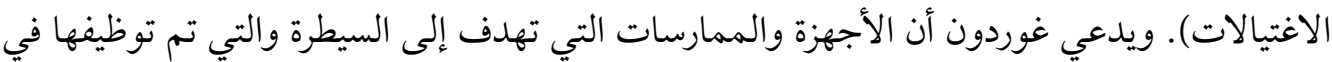

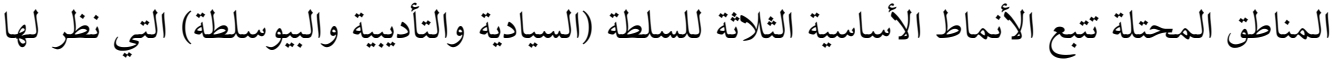

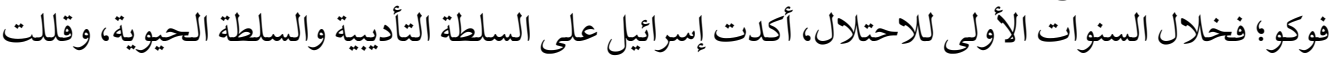

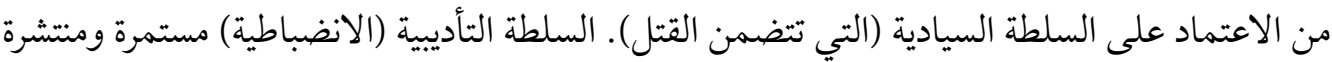

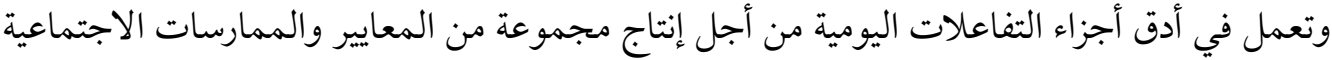

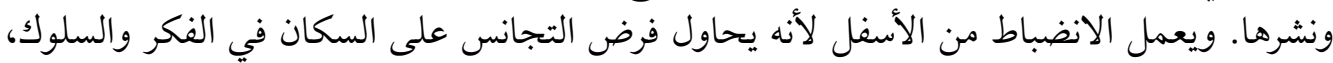

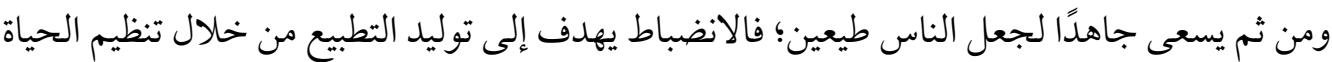

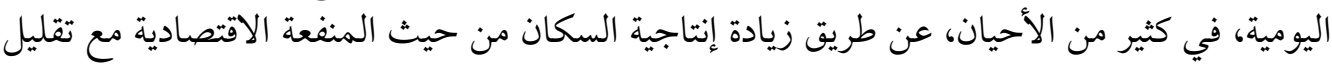

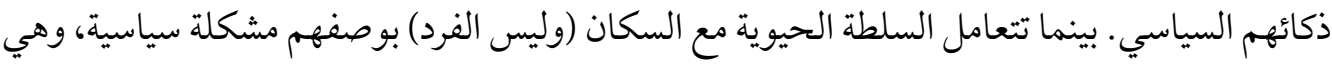

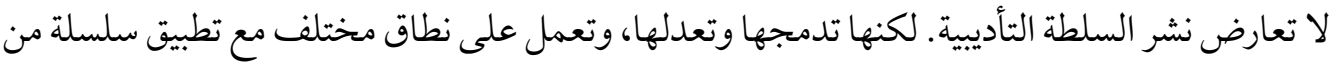

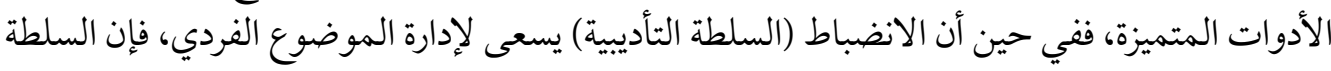

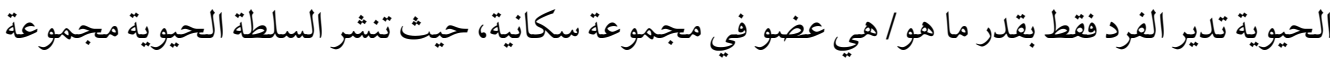

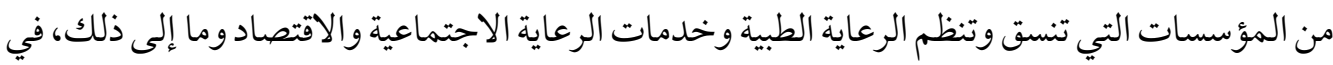

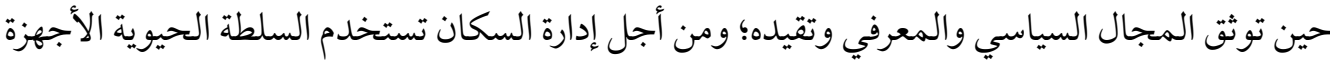

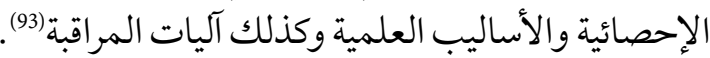

ويجادل ممداني بأن التطهير العرقي، بوصفه سياسةً، ناتجُ من الحداثة الأوروبية في سياق تأسيس

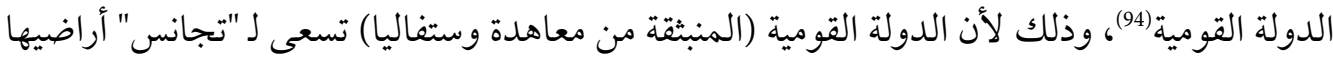
من خلال القضاء على الأقليات التي تحول دون ذلك، عن طريق ممارسة التطهير العرقي الذي يشمل

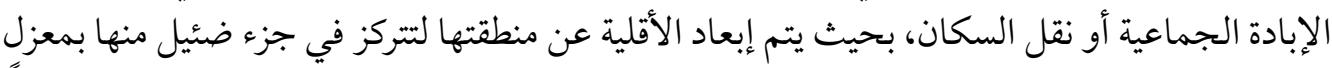
عن الأغلبية، ومن ثم فإن العنف الاستعماري وممارسة التطهير العرقي ضد السكان السان الأصلانيين، متأثرانً

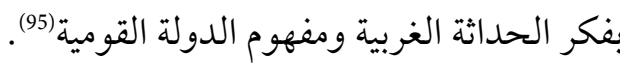

(92) Gordon, p. 5.

(93) Ibid., p. 11-12.

(94) في المقابل، تجادل حنّة أرندت بأنّ التطهير العرقي في المستوطنات الاستعمارية (التابعة للاستعمار الأوروبي) هو الذي وفّر

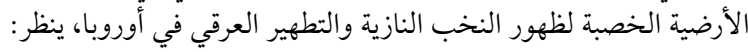

Hanna Arendt, The Origins of Totalitarianism (San Deigo/ New York/ London: A Harvest Book, 1973), p. 206.

(95) Mahmood Mamdani, Neither Settler nor Native: The Making and Unmaking of Permanent Minorities (Cambridge, MA: The Belknap Press of Harvard University Press, 2020), p. 4. 


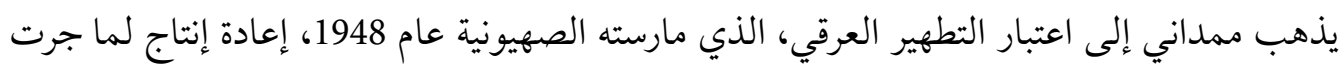

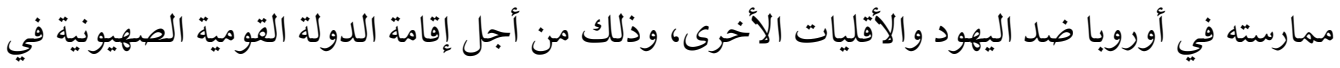

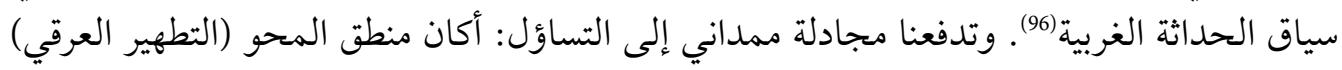

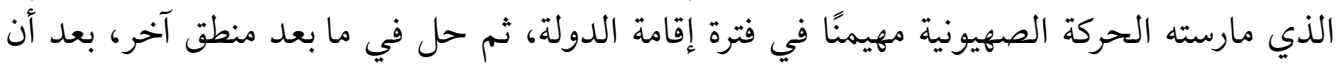

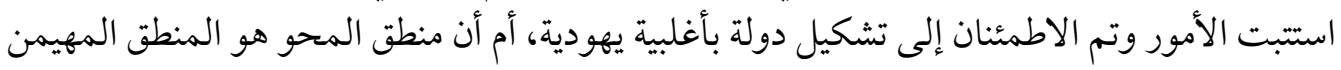

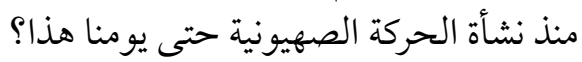

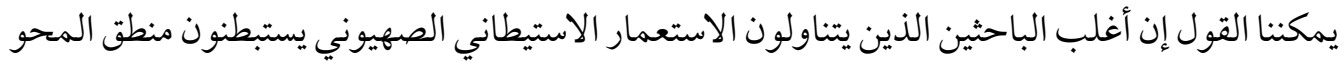

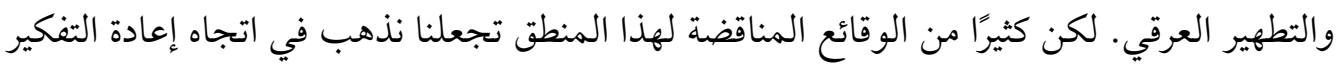

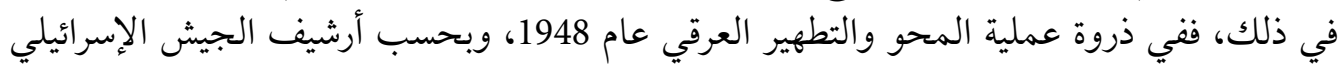

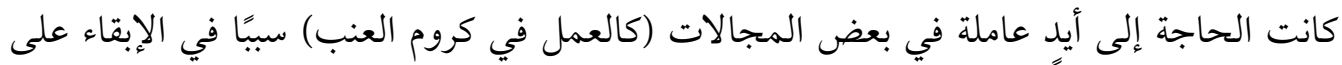

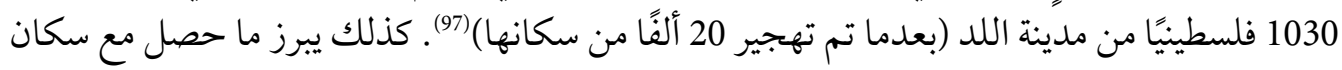

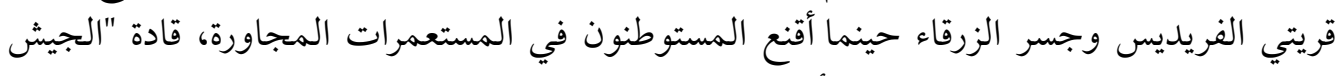

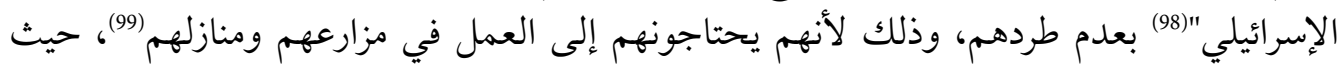

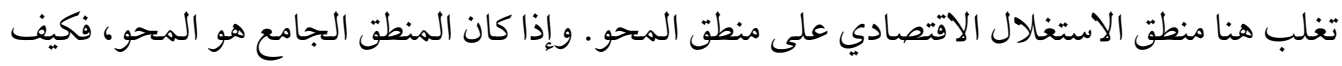

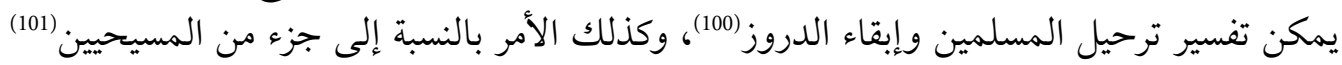

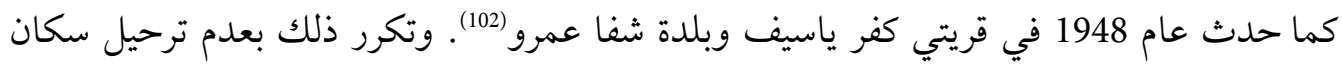

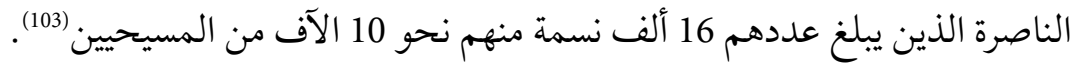

(96) Ibid., p. 27.

(97) حاييم يعكوبي، "المدن المختلطة: نحو فضاء مديني مضاد"، مجلة جدل، العدد 18 (تشرين الأول/ أكتوبر 2013)، ص 1،

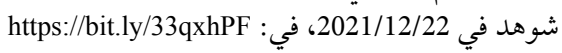
(98) في تلك الفترة لم يكن الجيش الإسرائيلي قد تأسس، إنما كانت ميليشيات صهيونية مسلحة.

(99) بابيه، ص 144 (100)

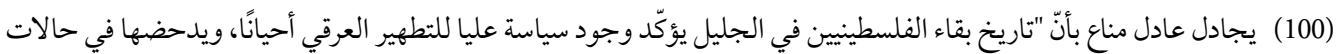

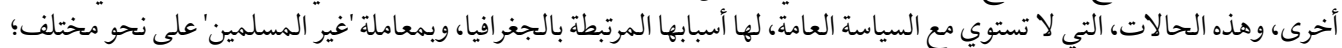

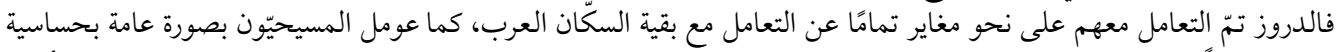

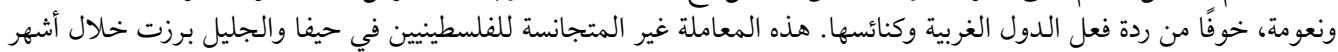

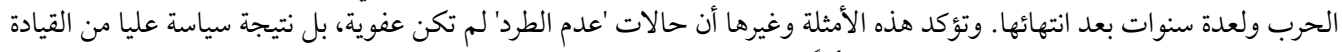

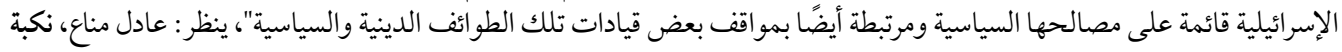

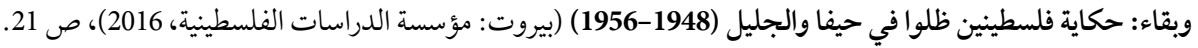

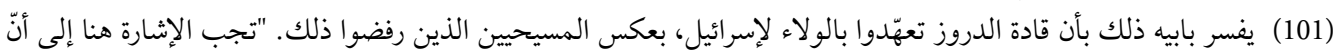

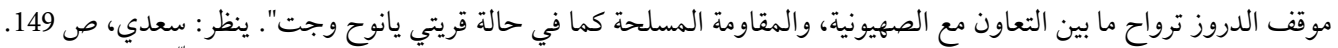

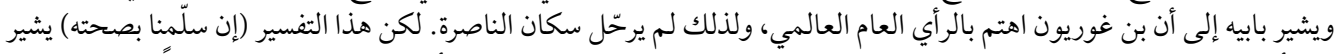

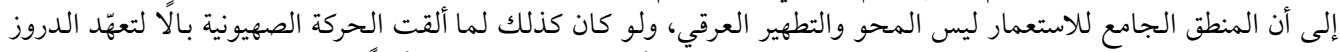

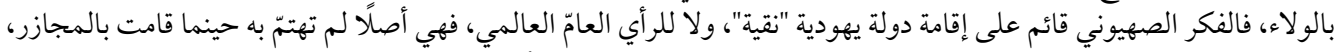

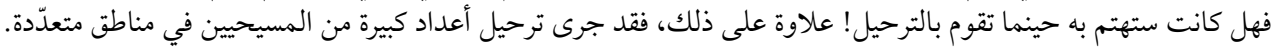


وإضافةً إلى ما سبق، إذا كان المنطق الجامع للاستعمار الاستيطاني الصهيوني هو المحو والتطهير

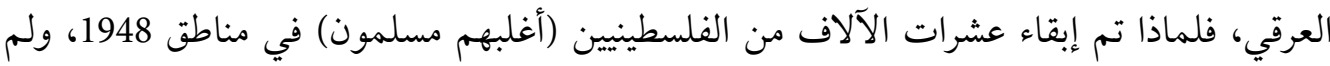

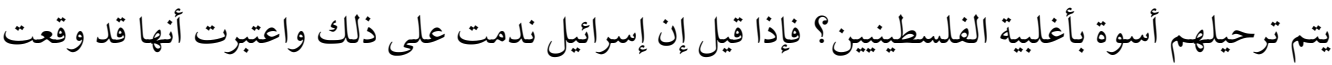

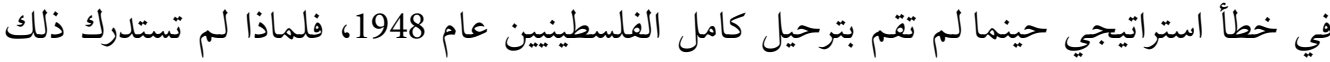
حينما سنحت لها الفرصة وواتتها الظروف لتهجير باقي الفلسطينيين كما حدث عاث عام 1956، حينما قامت

$$
\text { بمجزرة كفر قاسم، وأثناء الحرب على سيناء آتهاء }
$$

الأهم من ذلك هو ما حدث عام 1967، فإذا كان المنطق هو المحو والترحيل والتطهير العرقي، فلماذا

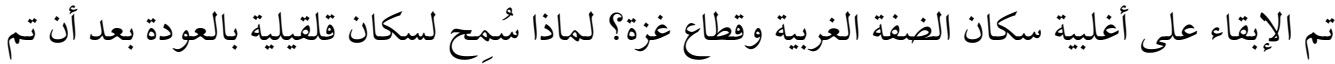

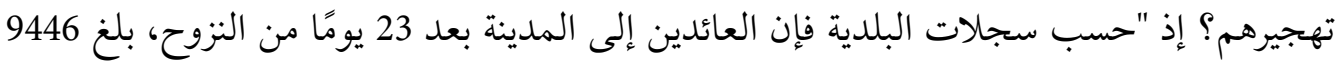

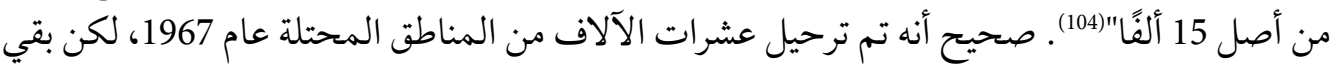

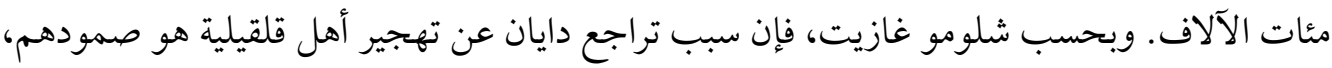

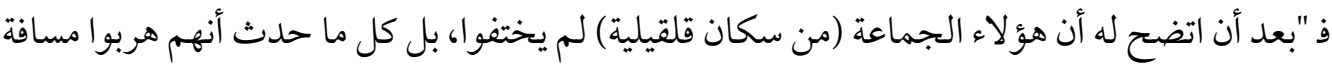

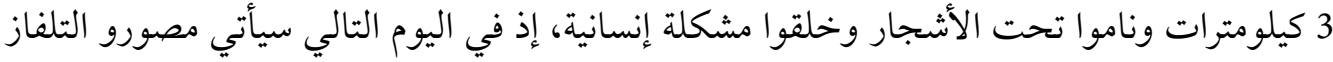

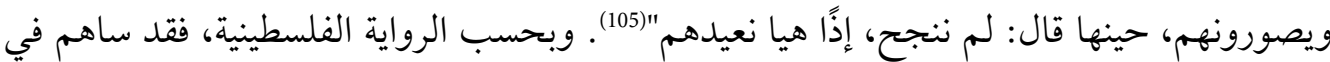

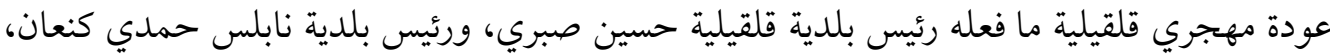

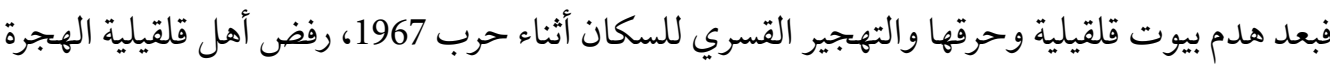

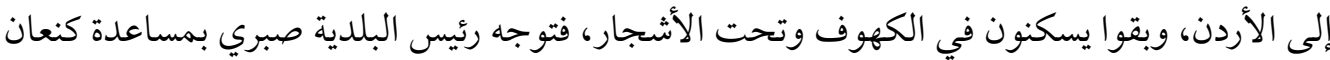

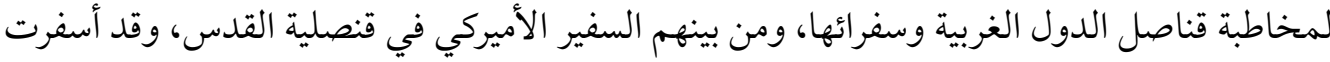

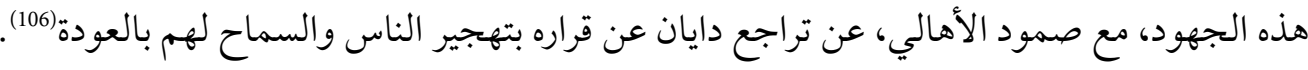
قد يقول قائل إن إسرائيل اتبعت سياسة التهجير التدريجي من خلال التضييق على الفلسطينيين

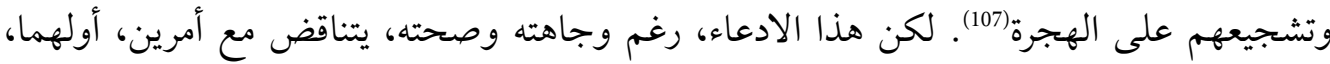

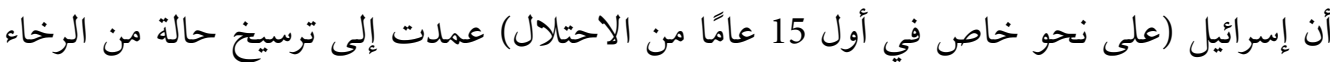

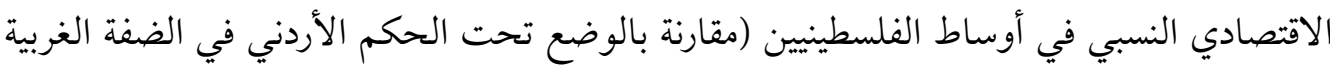

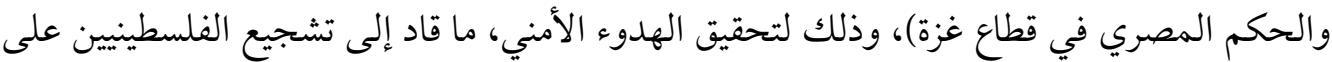

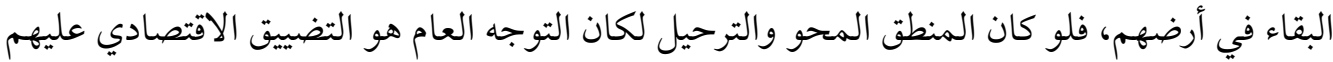
(104) يامن نوباني، "قلقيلية.. حين غيرت نكسة 1967 وجه المدينة"، إذاعة صوت فلسطين، 2018/6/5، شوهد في 2021/12/22،

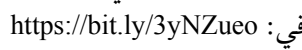
(105) "مقابلات مع أشخاص"، وثيقة رقم א-106/13) (5002/13، أرشيف دولة إسرائيل، 1985/4/26، ص 21 (بالعبرية) (106) ازدهار رابي، "قلقيلية وحرب حزيران 1967: دراسة وثائقية"، رسالة ماجستير، جامعة النجاح الوطنية، نابلس، 2001، صلئ ص وقد أكّد هذه المعلومة عبد الرحيم الحنبلي أثناء مقابلته. : (107) هذا ما تجادل به رنا بركات، ينظرة Rana Barakat, "Writing/ Righting Palestine Studies: Settler Colonialism, Indigenous Sovereignty and Resisting the Ghost(s) of History," Settler Colonial Studies, vol. 8, no. 3 (2018), pp. 349-363. 


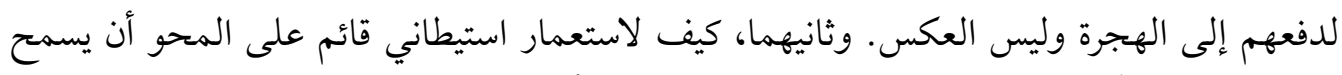

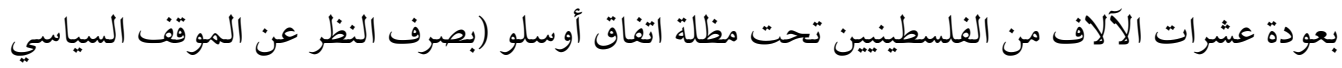

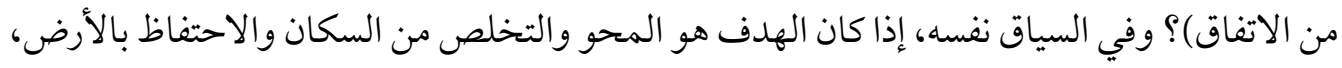

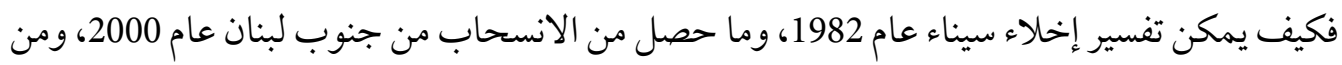

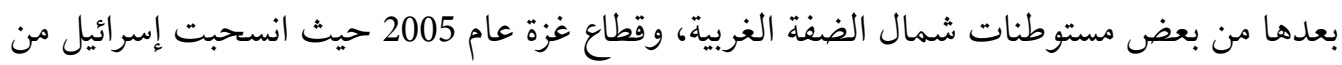
داخل القطاع لكنها أبقت على تحكمها وسيطرتها من الخارج؟

هنالك ملاحظة يجب أخذها في الاعتبار، هي ضرورة التمييز بين المحو وما يطلق عليه سعدي "إعادة

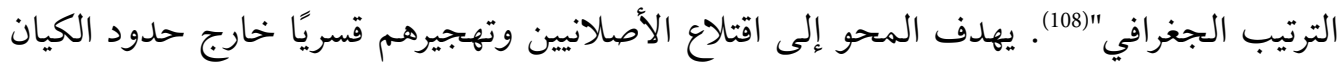

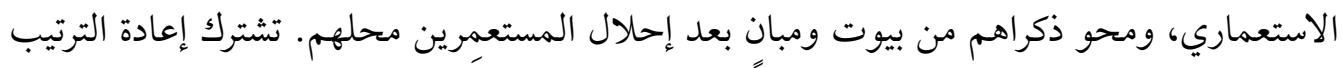

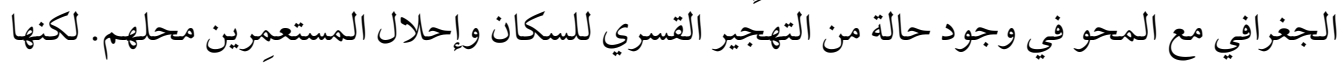

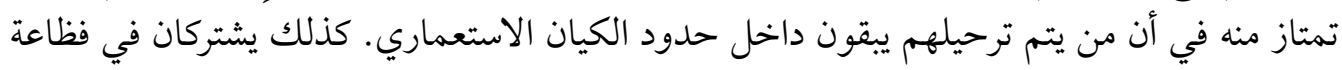

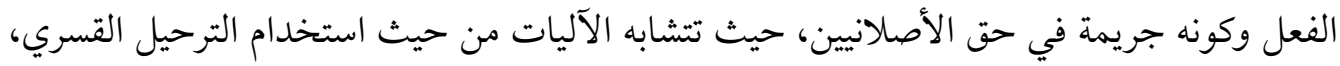

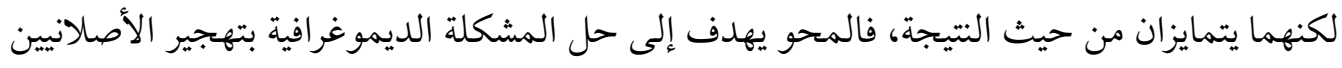

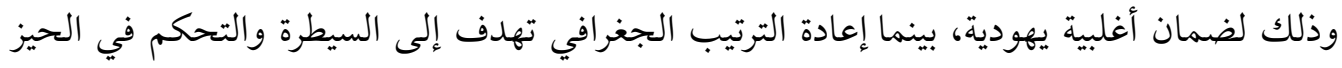

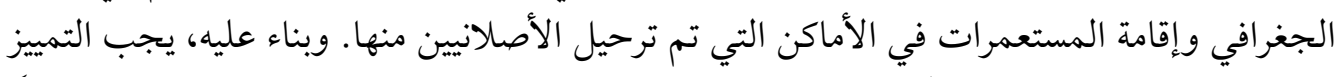

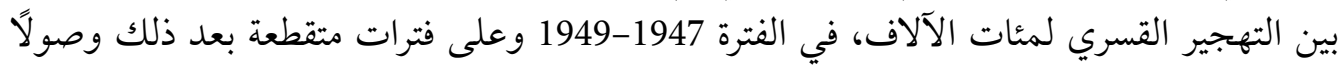

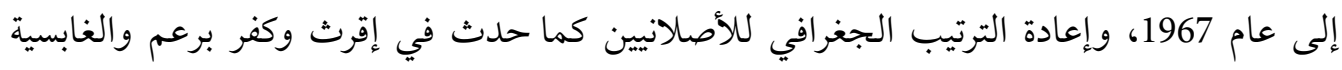

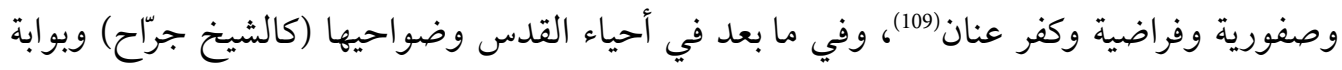

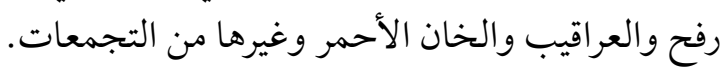

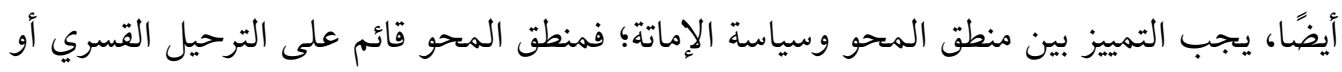

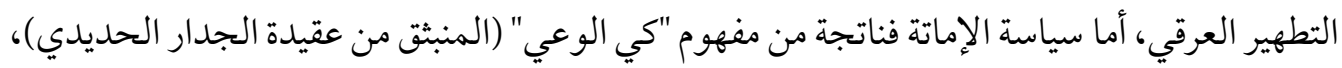

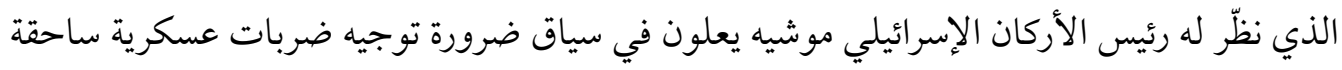

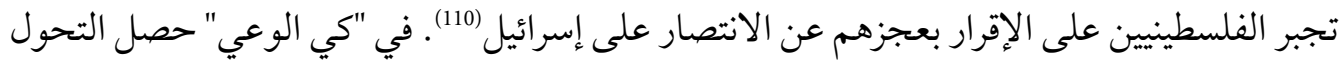

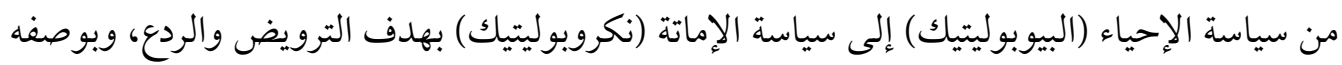

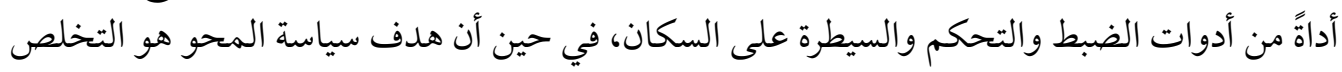

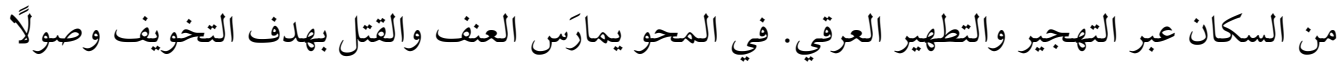

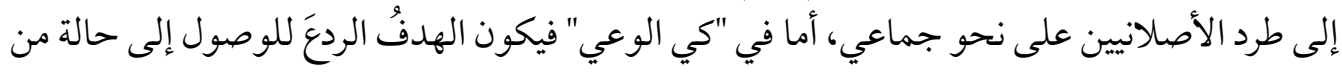
الضبط من دون أن يعني ذلك عدم تسبب سياسة "كي الوعي" في رحيل عدد من الأي فيكي الأصلانيين.

$$
\begin{aligned}
& \text { (108) (109) سعدي، ص } 74 . \\
& \text { (110) (108) المرجع نفسه. }
\end{aligned}
$$

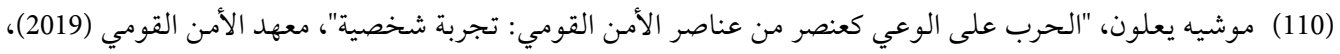


كل ما سبق ذكره يجعلنا نعيد التفكير في المنطق الجامع للاستعمار الاستيطاني الصهيوني، فلو كان

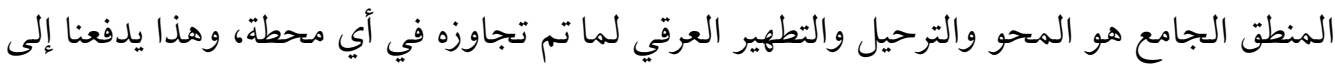
الادعاء بأن المنطق الجامع للاستعمار الاستيطاني في فلسطين هو السعي للتحكم و الضبط والتيط والسيطرة، من دون التقليل من أهمية الفاعلية الفلسطينية Agency في إفشال مخططات الترحيل الصهيونية؛

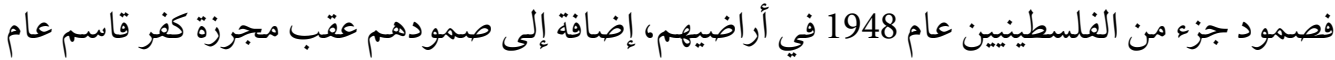

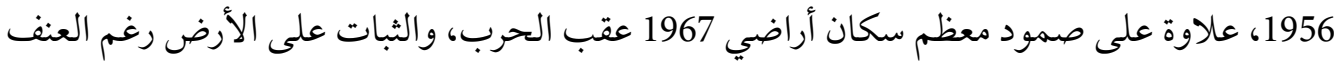
الوحشي الذي استخدم في انتفاضة الأقصى عام 2000، والإصرار على البقاء وعدم الرحيل على نحو

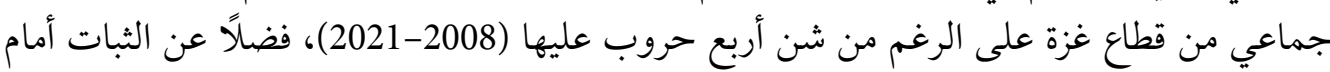
مخططات التهجير القسري وهدم البيوت كما هو متمظهر في قرية العراقيب والخان الأحمر؛ كل كل ذلك أك

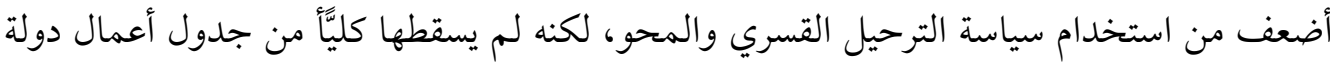
إسرائيل .

لا يعني تسيّد سياسة أو منطق في مرحلة من المراحل انتفاء وجود سياسة أو منطق آخر وعدم وجود

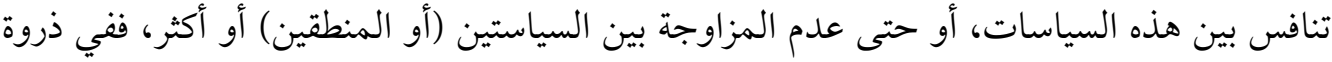
تبنّي منطق المحو عام 1948، ظهر منطق الاستغلال في عدم تهجير قريتي الفريديس وجسر الزرقاء

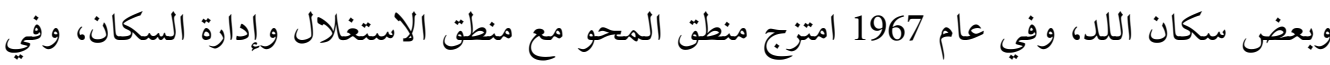
ذروة تبنّي منطق الفصل مع قطاع غزة كان هنالك تبنّي "كي الوعي"، ومؤخرًا التوجه إلى تبنّي منطق الاستيعاب مع الأبارتهايد عبر "خطة الضم".

يفسر تحليلنا موافقة سلطات الاستعمار الاستيطاني على عودة الآلاف من أفراد منظمة التحرير الفلسطينية تحت مظلة اتفاق أوسلو، بعكس المنطق المعروف عنه بسعيه الدائم للترحيل القسري؛

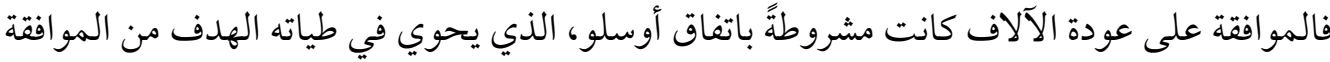

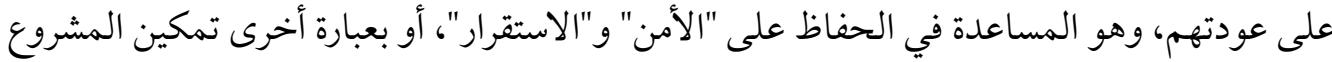

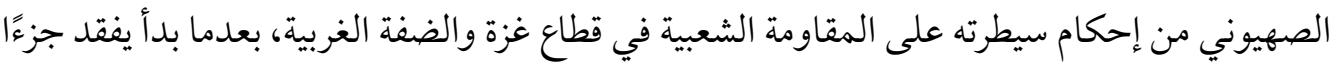
منها نتيجة انتفاضة عام 1987.

وعلى المنوال نفسه، يمكننا تفسير تخلي الحكومة الإسرائيلية عن "الأرض" في سيناء عام 1982، ولبنان عام 2000، وقطاع غزة عام 2005، بعكس المنطق الذي يقوم عليه الاستعمار الاستيطاني وهو

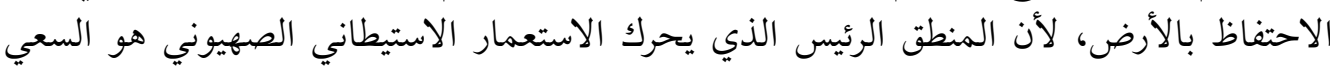

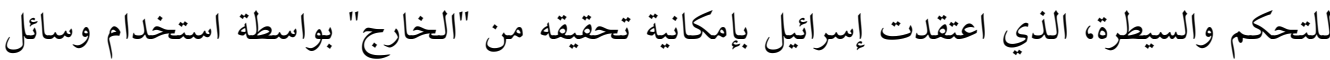

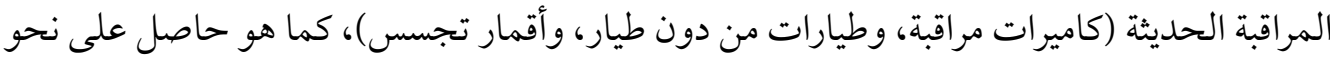

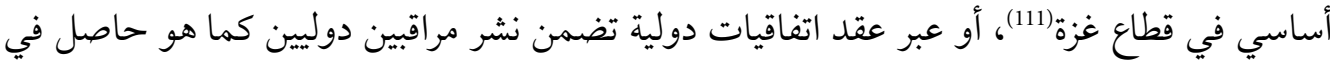
سيناء و جنوب لبنان. 


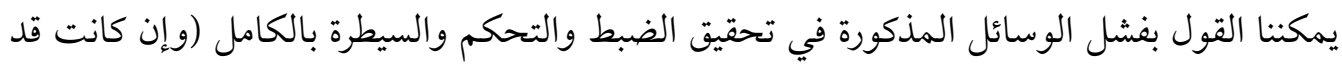

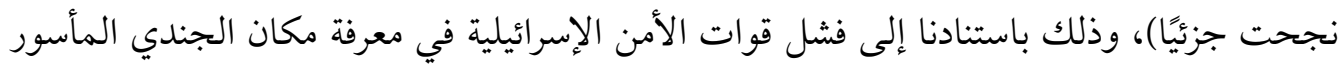

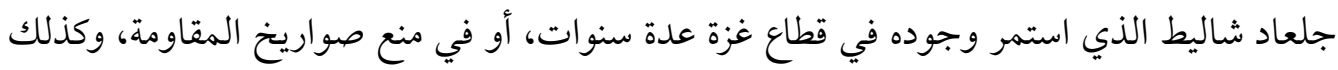

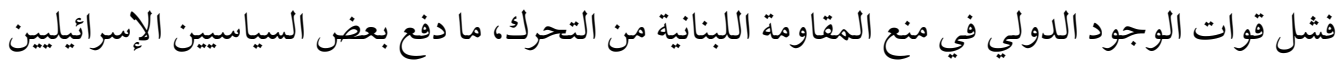

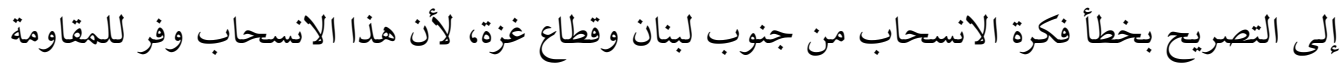

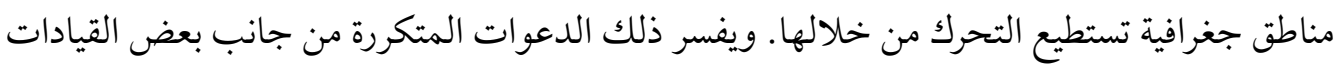

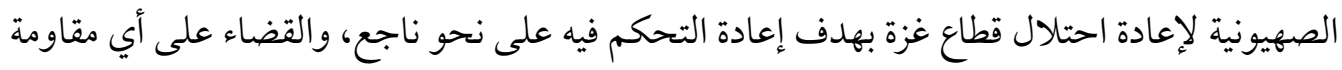
للمشروع الصهيوني.

\section{خَاتمة واستنتاجات}

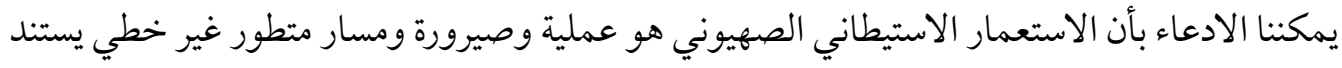

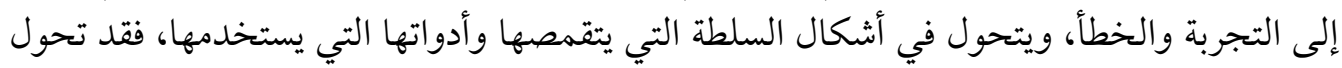

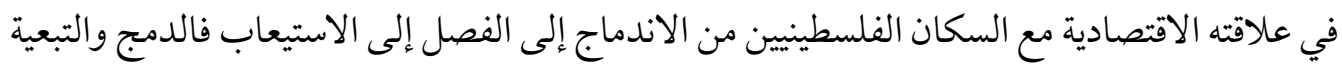
والاستغلال الاقتصادي، بما يحقق مصالحه ويخدم مشروعه.

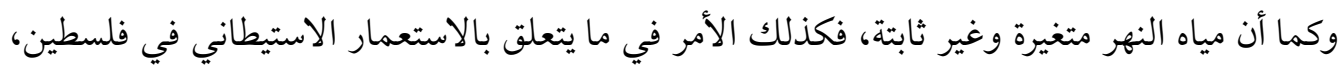

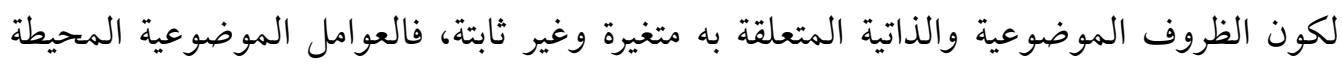

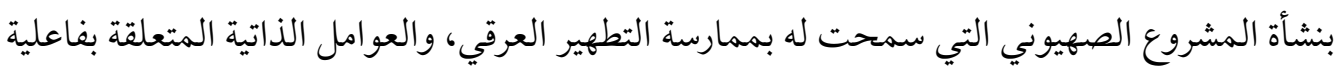

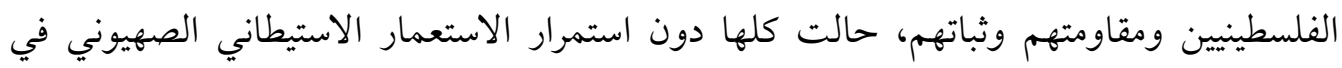

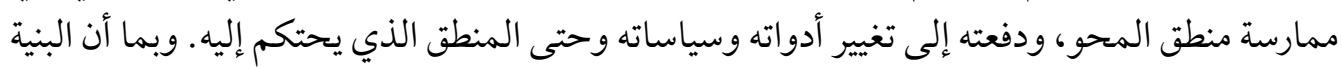

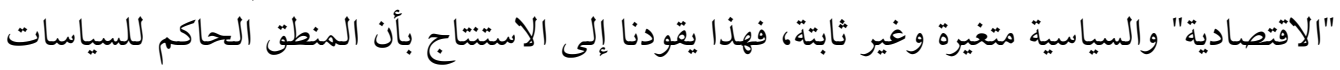

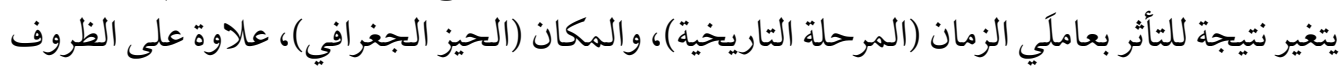
المحيطة (الفاعلون الداخليون والخارجيون)(112).

يجب التمييز بين المنطق الذي تحتكم إليه جميع السياسات وتنبثق منه، والسياسات المتنوعة التي

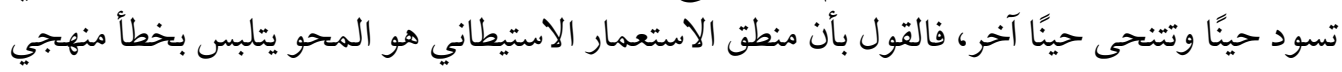

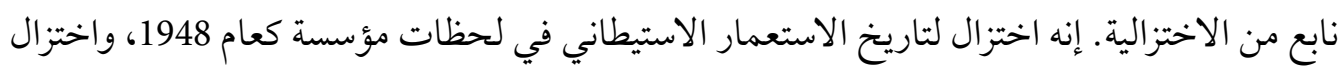

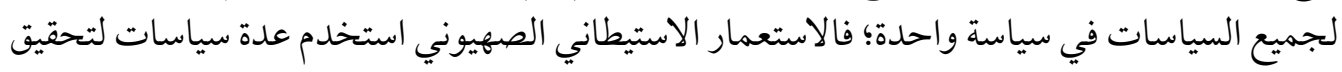

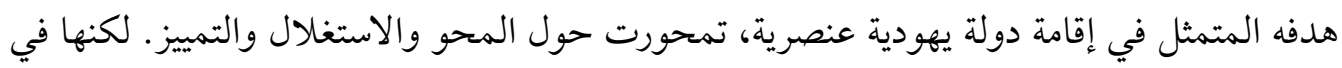

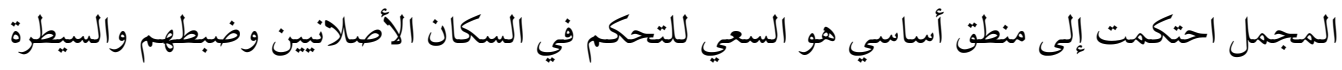

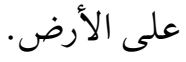

(112) ومثالًا على الفاعلية الخارجية يمكننا الاستشهاد باتفاقية كامب ديفيد مع مصر (بصرف النظر عن الموقف منها)، والتي قادت إلى إخلاء المستوطنات الإسرائيلية في سيناء. 
وبحسب التسلسل التاريخي لحالة الاستعمار الاستيطاني في فلسطين، يمكننا الادعاء بأنه يضع التحكم الإنم في الإنسان (الجسد الاجتماعي) والسيطرة على الأرض على رأس سلّم أولوياته، فبقدر "تدجينه"

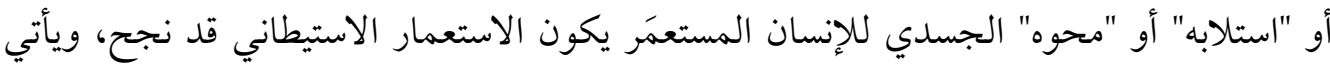
استهداف الأرض لأنها مصدر حياة الإنسان، بوصفها وسيلة إنتاج أساسية، واستمراره في الوجود في الحيز المستعمَر من ناحية، والذي هو حيز انطلاق مقاومة الاستعمار الاستيطاني من ناحية أخرى، فإذاذا

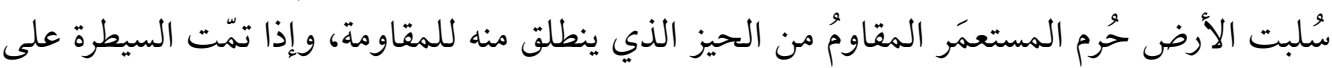

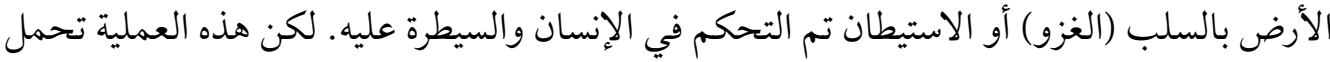

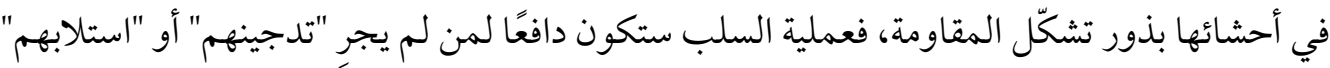

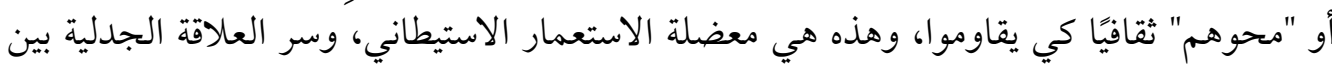

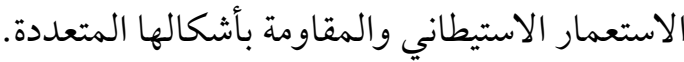

مارس الاستعمار الاستيطاني "المحو" الديموغرافي على نحو مباشر في فلسطين (أساسًا عام 1948

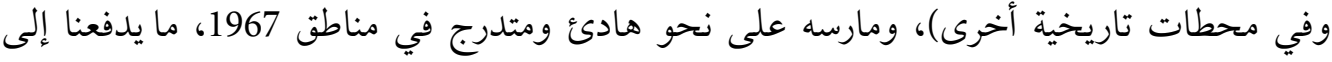

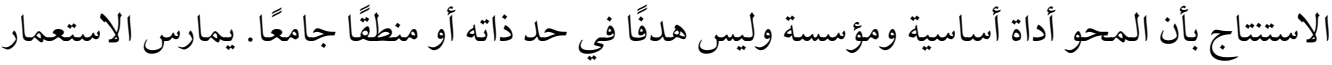
الاستيطاني المحو الديموغرافي لخشيته أو لعدم قدرته على السيطرة على هذا الإنسان والتحكمى فيه بسبب مقاومته للقوة الاستعمارية. لكن حينما يحقق الاستعمار الاستيطاني الضبط والسيطرة والتحكم في المستعمَر يتنحى السعي للمحو الديموغرافي، ويحل مكانه السعي لإدارة السكان (التحول من الإزالة إلى الإدارة)، والعكس صحيح، وذلك للمحافظة على الضبط والتحكم والسيطرة.

لا شك في أن المحو الديموغرافي والتهجير القسري والتطهير العرقي هي سمات أساسية ومؤسسة

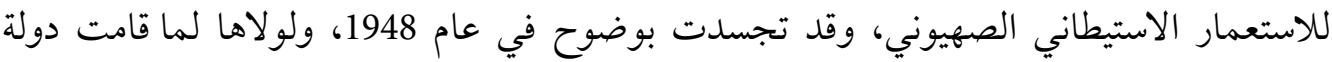

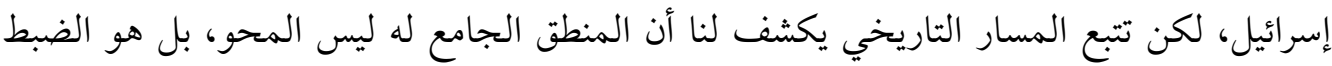

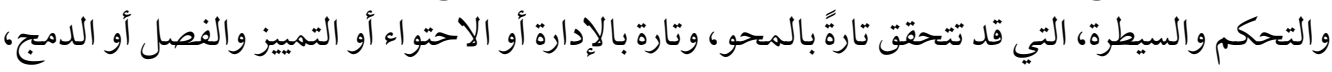
وذلك لتحقيق الهدف النهائي، وهو خدمة المشروع الصهيوني الاستعماري القائم على فكرة الدولة اليهودية العنصرية.

\section{References}

\section{المراجع}

العـربية

بابيه، إيلان. التطهير العرقي في فلسطين. ترجمة أحمد خليفة. بيروت: مؤسسة الدراسات الفلسطينية، 2007

بدر، أشرف وعاصم خليل. "الاستعمار الاستيطاني في السياق الفلسطيني: براديغم أم مفهوم؟". عمران. مج 9، العدد 35 (شتاء 2021). 
بشير، نبيه. "قراءة جديدة لعقيدة الجدار الحديدي: مرفق نص: النظرية الأخلاقية للجدار الحقيقي". مجلة قضايا إسرائيلية. العدد 69 (2018).

رابي، ازدهار . "قلقيلية وحرب حزيران 1967: دراسة وثائقية". رسالة ماجستير . جامعة النجاح الوطنية.

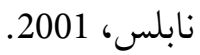

روحانا، نديم. "انتصار الصهيونية أو هزيمتها". مجلة الدراسات الفلسطينية. العدد 110 (ربيع 2017). روي، سارة. قطاع غزة: السياسات الاقتصادية للإفقار التنموي. ترجمة محمد طربية. بيروت: مؤسسة

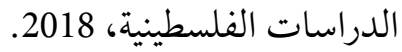

زريق، إيليا. "الصهيونية والاستعمار". عمران. مج 2، العدد 8 (ربيع 2014).

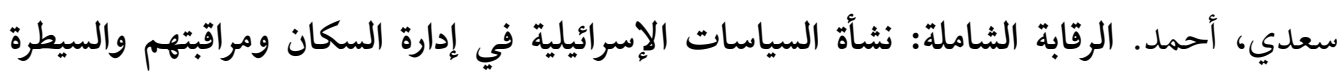

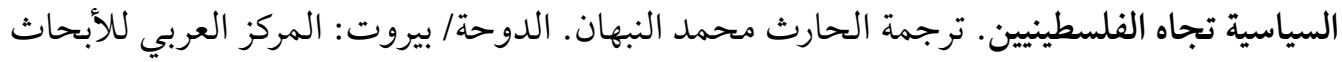
ودراسة السياسات، الساه غانم، هنيدة وعازر دكور (محرران). إسرائيل والأبارتهايد: دراسات مقارنة. رام الله: مركز مدار، 2018. فرسخ، ليلى. العمالة الفلسطينية في إسرائيل ومشروع الدولة الفلسطينية، 1967-2007. ترجمة سام برنر. رام الله: مؤسسة الدراسات الفلسطينة؛ بيروت: المؤسسة الفلسطينية لدراسة الديمقراطية -

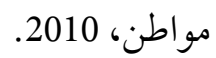

مناع، عادل. نكبة وبقاء: حكاية فلسطينيين ظلوا في حيفا والجليل (1948-1956). بيروت: مؤسسة الدراسات الفلسطينية، 2016.

يعكوبي، حاييم. "المدن المختلطة: نحو فضاء مديني مضاد". مجلة جدل. العدد 18 (تشرين الأول/ أكتوبر 2013). في: https://bit.ly/33qxhPF

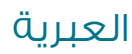

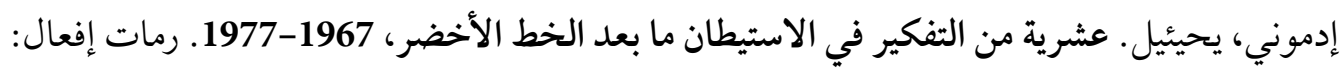
مركز يسرائيل جاليلي لبحث قوة الدفاع - يد تبنكين، الكيبوتس الموحمّد، 1992. "الأراضي المستحوذ عليها". وثيقة رقم גל-61315/4. أرشيف دولة إسرائيل. معهد عكيفوت. أشكول، ليفي. رئيس الوزراء الثالث: شهادات مختارة من حياته (1895-1969) . أرشيف دولة إسرائيل. القدس: دار كيتر للنشر، ائسئ الوزئ 2001.

بوميل، يائير. "أسس سياسات التمييز تجاه العرب في إسرائيل، 1948-1968". نظرة في قيام إسرائيل. مج 16 (2006). 


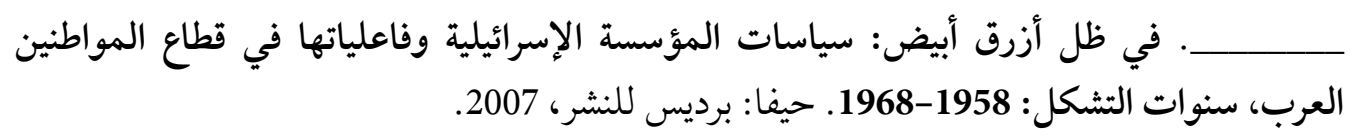

"ربط الاقتصاد العربي بالقطاع اليهودي في إسرائيل، 1967-1988". موقع ترابط.

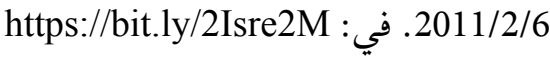

يعلون، موشيه. "الحرب على الوعي كعنصر من عناصر الأمن القومي: تجربة شخصية". معهد الأمن

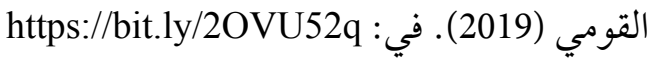

الأجنبية

Arendt, Hanna. The Origins of Totalitarianism. San Deigo/ New York/ London: A Harvest Book, 1973.

Barakat, Rana. "Writing/ Righting Palestine Studies: Settler Colonialism, Indigenous Sovereignty and Resisting the Ghost(s) of History." Settler Colonial Studies. vol. 8, no. 3 (2018).

Bateman, Fiona \& Lionel Pilkington (eds.). Studies in Settler Colonialism: Politics, Identity and Culture. New York: Palgrave Macmillan, 2011.

Bäuml, Yair. "MAPAI Committee for Arab Affairs: The Steering Committee for Construction of Establishment Policy towards Israeli Arabs, 1958-68." Middle Eastern Studies. vol. 47, no. 2 (March 2011).

Foucalute, Michel. Society must be Defended. New York: Picador, 2003.

Gordon, Neve. Israel's Occupation. Berkeley/ London: University of California Press, 2008.

Hillal, Jamil. "Imperialism and Settler Colonialism in West Asia: Israel and the Arab Palestinian Struggle." University of Dar es Salaam Journals. vol. 1, no. 1 (1976).

Kimmerling, Baruch. The Invention and Decline of Israeliness: State, Society and the Military. Berkeley: University of California Press, 2001.

LIoyd, David. "Settler Colonialism and the State of Exception: The Example of Palestine/Israel." Settler Colonial Studies. vol. 2, no. 1 (2012).

Mamdani, Mahmood. Neither Settler nor Native: The Making and Unmaking of Permanent Minorities. Cambridge, MA: The Belknap Press of Harvard University Press, 2020.

Pappe, Ilan. The Biggest Prison on Earth: A History of the Occupied Territories. London: Oneworld Publications, 2017.

Ranta, Ronald. The Wasted Decade Israel's Policies towards the Occupied Territories 1967-1977. London: London's Global University, 2009.

Segev, Tom. 1949: The First Israelies. New York: An Owel Book, 1998. 
Shafir, Gershon. Land, Labor and the Origins of the Israeli-Palestinian Conflict, 1882-1914. Berkeley: University of California Press, 1996.

2017.

. A Half Century of Occupation. Berkeley: University of California Press,

Svirsky, Marcelo \& Ronnen Ben-Arie. From Shared Life to Co-Resistance in Historic Palestine. London/ New York: Rowman \& Littlefield International Ltd, 2018.

Veracini, Lorenzo. Settler Colonialism: A Theoretical Overview. Basingstoke: Palgrave Macmillan, 2010.

. "The Other Shift: Settler Colonialism, Israel and The Occupation." Journal of Palestine Studies. vol. 42, no. 2 (2013).

. "Settler Colonialism: Career of a Concept." The Journal of Imperial and Commonwealth History. vol. 41, no. 2 (2013).

. The Settler Colonial Present. New York: Palgrave Macmillan, 2015.

Wolfe, Patrick. Settler Colonialism and the Transformation of Anthropology. London/ New York: Cassell, 1999.

. "Settler Colonialism and the Elimination of the Native." Journal of Genocide Research. vol. 8, no. 4 (2006). 